\title{
Structural Integrity Assessment of Floating Offshore Wind Turbine Support Structures
}

\author{
Behrooz Tafazzoli Moghaddama, Ali Mahboob Hamedanya, Jessica Taylor ${ }^{\mathrm{a}}$, Ali \\ Mehmanparast ${ }^{\mathrm{a} *}$, Feargal Brennan ${ }^{\mathrm{b}}$, Catrin Mair Davies ${ }^{\mathrm{c}}$, Kamran Nikbin $^{\mathrm{c}}$ \\ ${ }^{a}$ Offshore Renewable Energy Engineering Centre, Cranfield University, Cranfield, MK43 OAL, UK. \\ ${ }^{b}$ Department of Naval Architecture, Ocean and Marine Engineering, University of Strathclyde, Glasgow, G1 1XQ, UK. \\ ${ }^{c}$ Department of Mechanical Engineering, Imperial College London, South Kensington Campus, London, SW7 2AZ, UK.
}

*corresponding author: a.mehmanparast@cranfield.ac.uk

\begin{abstract}
Floating offshore wind turbines are becoming more attractive to the wind industry due to their capability to operate larger turbines in deeper waters. The floating support structures are anchored to the seabed via mooring chains to impede the structure's unwanted movements. The combination of cyclic stresses and the corrosive marine environment makes the floating support structures vulnerable to corrosion pitting and subsequently fatigue crack initiation and propagation. In this study a framework is proposed to simulate fatigue crack growth from multiple corrosion pits at critical spots of the Spar-type floating support structures to examine the status of the crack during several years of operation. The proposed advanced fracture mechanics based approach provides a methodology to assess the integrity of the structure and subsequently plan for preventive or curative maintenance. The crack growth rate is examined for both singular and multiple cracks at different $R$ ratios and for different stress levels using ABAQUS XFEM. Following numerical simulations, a sensitivity analysis is carried out using Crackwise software for different values of plate thickness, $R$ ratio and initial crack size. The numerical results are discussed in terms of the corrosion pitting effects on fatigue life assessment of floating offshore wind turbines.
\end{abstract}

Keywords: pitting corrosion, corrosion fatigue crack growth, floating offshore wind turbine, Spar foundation, defect assessment 
This is a peer-reviewed, accepted author manuscript of the following article: Moghaddam, B. T., Hamedany, A. M., Taylor, J., Mehmanparast, A., Brennan, F., Davies, C. M., \& Nikbin, K. (2020). Structural integrity assessment of floating offshore wind turbine support structures. Ocean Engineering, 208, [107487]. https://doi.org/10.1016/j.oceaneng.2020.107487

\section{Introduction}

The increasing demand to produce electricity from clean and sustainable sources of energy has led to enormous expansion of the offshore wind industry. Offshore wind turbines, in contrast to onshore wind turbines, have higher wind power production rate and longer lifespan. Therefore, due to stability and reliability of offshore wind sources, this industry has received more and more attention from investors in recent years [1]. RenewableUK's Offshore Wind Project intelligence reported that the global offshore wind projects have increased from 95 GW in 2017 to 104 GW in 2018 [2]. The European Wind Energy Association (EWEA) estimates that Europe's offshore wind capacity will reach $64.8 \mathrm{GW}$ by 2030 , which supplies $8.4 \%$ of the total demand [3]. Europe's installed offshore capacity is near $18.5 \mathrm{GW}$ while the UK is leading the market with $44 \%$ of the installations in MW [4]. At the end of 2018, there were nearly 2000 operational offshore wind turbines in the UK and thousands more are planned (floating and bottom fixed) to meet the 2020 targets, according to EU strategic energy technology plan (SET-plan) [5]. In addition, the average size of new offshore wind turbines installed in 2018 was $6.8 \mathrm{MW}$, which is $15 \%$ larger than the turbines installed in 2017, with the largest turbine in the world being installed in the UK (8.8 MW by Vestas Offshore Wind) [4]. For this increasing volume of offshore wind structures, reducing the operational costs is an important factor considering the limited profit margin in offshore wind energy and by knowing that the turbines need to operate closer to their true design capacity [6].

The dominant majority of installed offshore wind turbines are based in shallow waters near the shores and as the suitable shallow water sites are becoming scarce, more countries are now planning for floating wind farms. The floating wind farms become more economical for deeper waters and unlike onshore wind, they are not constrained by regulatory problems such as visual or noise pollution [7], therefore floating offshore wind turbines can have larger support structures for increased efficiency. Stronger and more consistent wind streams means generating more power. However, the structure needs to sustain harsher loading conditions in deeper waters besides being further away from the shore, makes monitoring and inspection more difficult and costly.

The foundation of floating wind turbines is a key component in the structure's stability and integrity. Spar type foundations are one of the most common types of floating support structures, which are mainly made of welded steel plates. The foundation is continually subjected to large stochastic cyclic loads caused by wind and wave fluctuations. The combined effect of the corrosive contents of seawater and the cyclic stresses can be detrimental to the foundation [8], particularly in regions with high stress concentration and lower corrosion resistance. The connection points between the mooring lines and the floating foundation are susceptible to both. Submerged welded joints with high probability of corrosion pitting and the cyclic stresses from the mooring lines makes these connections a critical integrity concern in the structure. DNV J101 suggests cathodic protection for external surfaces of submerged structures [9]. Even where protective coating, cathodic protection or other preventive methods are used, the likelihood of corrosion loss must not be neglected over long periods of time [10]. Considering the long time-horizon of the structural tests compared to design time-frames, models are required for prediction of the structures performance [11].

Corrosion pits cause local stress concentration in the WM (Weld Metal) and HAZ (Heat Affected Zone), which have a high likelihood for fatigue crack initiation and growth. In order to assess the fatigue life in the floating foundations, it is crucial to probe the fatigue crack initiation from corrosion pits in the mooring points. The corrosion fatigue process has different stages; the surface breakdown and pit creation/growth, pit-to-crack transition, and crack growth [8]. The latter consists of small crack and long crack growth regimes. Continuous crack growth under corrosion fatigue conditions occurs when a crack is initiated and then grows with a higher rate than the pit growth [12]. The pit macro-topology and the state of stress and strain fields around the pits, along with plastic strain concentration, control the transition from pit to crack [13]. Kondo's model was one of the first solutions to describe the pit growth 
This is a peer-reviewed, accepted author manuscript of the following article: Moghaddam, B. T., Hamedany, A. M., Taylor, J., Mehmanparast, A., Brennan, F., Davies, C. M., \& Nikbin, K. (2020). Structural integrity assessment of floating offshore wind turbine support structures. Ocean Engineering, 208, [107487]. https://doi.org/10.1016/j.oceaneng.2020.107487

rate and the stress intensity factor for the critical condition of a pit with constant aspect ratio. Later, Hoeppner developed a model to calculate the critical pit depth for crack nucleation under Mode I crack opening [14]. Similarly, Lindley [15] provides a critical pit depth with a critical stress intensity factor for crack growth from pits. Kawai and Kasai used experimental data for stainless steel to define a threshold SIF [16]. More detailed models such as [17] [18] and [19] offer formulation for critical pit size as well as the cyclic crack growth rate after the transition to a short or long crack.

In the present study, the load analysis is carried out using Hydrodyn and FAST software [20] based on operational wind speeds, and not storm events, which is the focus of this project. FAST is a CAE tool for the simulation of dynamic response of wind turbines that can integrate elastic analysis, control/electrical systems (servo) and hydrodynamic analysis. The time-domain hydrodynamic analysis is done by Hydrodyne software, coupled with FAST.

The loads are characterized and grouped into simplified load cases using Rainflow cycle counting technique [21] [22] and [23]. On the other hand, defect assessment analyses using failure assessment diagrams [24] [25] [26] are also carried out in order to give an estimate of the critical crack sizes and evaluate the structure's resistance to critical loading conditions when corrosion cracks are present in the structure.

The present study is focussed on the fatigue crack propagation behaviour of long cracks initiated at corrosion pits, and does not involve the time period required for a crack to initiate neither transition from short crack to long crack. Whether the initiation time is predicted based on available models or, the cracks are detected using NDT methods, this work aims to address the behaviour of the crack after long cracks are identified and investigate how they behave under cyclic loads in floating structures. Moreover, this study includes a general assessment of the crack status over the time period between initiation from a long crack and failure.

In this study, the corrosion fatigue analysis is carried out for the mooring point section of the foundation which undergoes millions of cycles over several decades. For this, a numerical approach is developed to simulate the crack growth from pits on critical spots on a mooring point for stochastic loads over several years of operation. The cracks are defined explicitly using ABAQUS XFEM finite element (FE) software and a direct cyclic solver is employed to simulate the crack growth over millions of cycles. Empirical data on pit dimensions are used to define the crack geometry. Given that the amount research on the pitting profile for submerged or tidal steel structures is scarce, the limited available data on pit geometry from [27] are used to define an approximate pitting/crack profile to represent the state of the material in the corrosive environment. The pits/cracks are generated in $2 \mathrm{D}$ form, representing a crack initiated from a corrosion pit with a non-uniform random distribution of pit depth sizes and a uniform distribution over the pitting area. There are many possible combinations of pit size, locations, timespan and other factors for this type of fatigue analysis. In the present study, the aim is to consider as many influential factors as possible and to eliminate the non-critical scenarios. This study focusses on development of the numerical framework for floating foundations, with a few case studies and more detailed analysis, for instance on uncertainty in corrosion pit geometry or weld toe geometry, will be examined in future study.

According to BS7910, the structural integrity of welded structures heavily relies on stress-based assessments on the unflawed structure [24]. If an unflawed model without stress concentrators such as weld toes is used, for flaws near weld toes and stress concentrators, the stress intensity factor can be used for the geometry of the flaw and multiplied by the stress values obtained from the FE analysis. The FE analysis for unflawed structures does not require a fine mesh, however DNVC203 suggests at least two second order elements over the throat thickness [28]. Shell or solid elements can be used for continuous models but when the crack geometry is modelled, 3D solid elements are required. 3D solid elements also allow calculation of the through thickness stress distribution in welded plates. According 
This is a peer-reviewed, accepted author manuscript of the following article: Moghaddam, B. T., Hamedany, A. M., Taylor, J., Mehmanparast, A., Brennan, F., Davies, C. M., \& Nikbin, K. (2020). Structural integrity assessment of floating offshore wind turbine support structures. Ocean Engineering, 208, [107487]. https://doi.org/10.1016/j.oceaneng.2020.107487

to DNVC203 standard, at least two or three elements are suggested for the through thickness direction [28].

The stress analysis data are usually used in conjunction with S-N curves for life assessment and the fracture mechanics approach is mainly used for assessment of acceptable defects and evolution of acceptance criteria for inspection planning [28]. The crack initiation phase is not currently included in the fracture mechanics analysis and the initiation time has to be added separately. The cracks are assumed to grow perpendicular to the stress component that opens the crack and compressive stresses do not contribute to the propagation, although the effect of residual stresses should not be ignored and the complete stress range should be applied.

For fatigue assessments, fluctuating stresses are considered as primary stresses. It's worth noting that the structural discontinuities do not change the primary or thermal stresses nor the secondary stresses [24]. In real life practice, the flaws are characterized by NDT or other means of measurement. If multiple cracks are present, the proximity of the cracks can define whether they interact with each other or not. For the present work, XFEM is capable of modelling the crack coalescence and it is possible to model it explicitly. In this way, since the fracture mechanics parameters are measured for each crack, no adjustment with stress intensity factor or secondary adjustment for the stresses are needed. The corrosion cracks are considered to be perpendicular to the maximum principal stress vector. If the crack is non-planar or if there is misalignment, the approach is still conservative and can be applied in the numerical analysis [24].

\section{Methodology and Modelling Approach}

In the current study, an advanced fracture mechanics based approach has been employed to model the crack propagation from corrosion pits located at the intersection point between the mooring line and the floating foundation. The model is created in ABAQUS v6.14-4 standard [29]. The floating support structures are conventionally anchored to the seabed using three mooring lines, however in this study only one mooring line, which is under tension, has been considered and its connection point with the foundation has been analysed. In order to perform the analysis efficiently, only the areas with great stress values and high probability of developing corrosion cracks are used for inclusion of the corrosion pits on the floating structure. In this regard, quasi-static simulations are initially carried out with the real loads on the structure, without including any defect in the model, to identify the hot spot regions which are at the higher risk of crack initiation and propagation. The stresses from the intact structure are also employed in a defect assessment analysis using Crackwise, a software which performs defect assessment based on BS7910 procedure [24], which is explained in section 6.2.2. Crackwise results.

The dimensions of the pits are taken from the available experimental data [27] for similar operational conditions. The data presented in [27], which is the most suitable data set available in the literature, is employed in this study and an approximate distribution of extreme values of pit depth is made to create a mild or severe pitting profile in the structure at a given operational life time. The pits are generated in 2D and 3D using a python script in ABAQUS. The dimensions are selected from a non-uniform distribution of possible depths, which is defined as arrays of possible depths with their frequency of occurrence, and uniformly distributed over the target surface.

The crack growth from corrosion pits is modelled in the form of elliptical cracks with the dimensions derived from the dimensions of the pits. Both 2D and 3D pits have been considered and modelled, however no significant difference was observed between the two. In both cases, a 2D crack surface had to be defined, cutting into the element domain. This describes the similarity of the results in 2D and $3 \mathrm{D}$ mode, since the crack discontinuity influence is much more dominant than the pit dimensions. 
This is a peer-reviewed, accepted author manuscript of the following article: Moghaddam, B. T., Hamedany, A. M., Taylor, J., Mehmanparast, A., Brennan, F., Davies, C. M., \& Nikbin, K. (2020). Structural integrity assessment of floating offshore wind turbine support structures. Ocean Engineering, 208, [107487]. https://doi.org/10.1016/j.oceaneng.2020.107487

Therefore, given that for the wide range of dimensional features in the model, 3D simulation for pits does not offer much more detail, and considering the excessive additional computational time required for 3D pits, it was decided to focus this study on 2D corrosion pits.

In this study it has been assumed that the pit depth and aspect ratio are different at each time period. There are three regions defined for pit density/severity including HAZ, WM and base material (BM). In reality, the pits grow as time passes but in order to numerically implement the corrosion fatigue crack growth, the crack propagation from a corrosion pit has been analysed at a given time, in isolation from pit evolution, and the fatigue crack growth analysis is carried out to explore if the rate of the crack extension exceeds the general corrosion (GC) rates. The focus of this study is to assess the growth of the long crack and to investigate whether or not the crack develops into the critical stage where catastrophic failure may occur.

One of the most important parts of the simulation is definition of the loads in ABAQUS simulations. As shown and explained later in section 5.3. Rainflow-cycle count, the data consists of 66 combinations of wave and wind speed cases. In order to use the data for fatigue analysis, the Rainflow-cycle counting [21] [30] technique is used to analyse the cyclic loads and their frequency, amplitude and mean values. Subsequently, the analysed data are employed in ABAQUS direct cyclic solver to simulate the crack growth over the defined time periods.

ABAQUS direct cyclic solver uses the Paris law constants for the crack growth simulation [31]. Multiple cracks are considered for the simulation to examine the possibility of crack coalescence as well as performing crack propagation analysis. The software measures the energy release rate for each crack and calculates the crack extension over a number of cycles. For a given pit profile, the analysis is carried out initially for a two-year duration in order to compare the crack growth rate with that of general corrosion. The cracks that exceed the general corrosion rate are tested in Crackwise for a 20-year duration to see if the crack reaches a critical value beyond which catastrophic failure will occur.

\section{Corrosion Pitting and Thickness Reduction}

\subsection{Pit depth and density distribution}

For mild steel, during the initial stages of exposure to marine immersion condition, pits with radius of 100-200 micron appear at the outer surface of the structure [32]. Most of the micro-pitting happens at the early stages of exposure [33]. The pit profile becomes wider as time passes, particularly for modern steels. Given the stochastic nature of corrosion pitting, techniques such as extreme value statistics [34] are often used to predict the pit depth distribution when the measurements are taken over a small area and applied for a prediction over a larger area. If the chosen area is too small, the probability of obtaining the maximum pit depth might be underestimated. In other words, the probability of having the largest possible pit increases as the considered area size is increased. The extreme value statistic is entirely empirical and does not have a theoretical connection to the pitting corrosion [32]. In reality, the pitting process continues adding new corrosion pits, and the longer the exposure time the more variability is present in the pit sizes. According to the experimental results reported in [35], most of the pits are generated in the initial stage of the exposure and the rate of new pit formation decreases with time. This decrease in new pit formation is related to the modification of the pitting surface and is associated with the fact that the surface becomes less sensitive to pitting when there are pre-existing pits on it [36].

The number of pits can be described by a non-linear power law trend line fitted to the experimental data, however the models based on short-term observations do not correlate well with the longer exposure time and usually overestimate corrosion pitting at longer times [10].The closest experimental data to the present study is the work of Chavez et al [27]. They considered three zones of a welded specimen; heat affected zone (HAZ), base material (BM) and weld material (WM) and followed a set of 
the 5 deepest pits on each zone during the experiment time of 3.5 years. This test was performed on API X56 Spec $5 \mathrm{~L}$ grade steel pipeline in the Pacific Ocean and 15 major pits in $100 \times 50 \mathrm{~mm}$ coupons were found in the three material microstructures. For the range of pits observed initially in steel samples in seawater, the suggested range of density is between $0.014-0.02 \mathrm{pits} / \mathrm{mm}^{2}$.

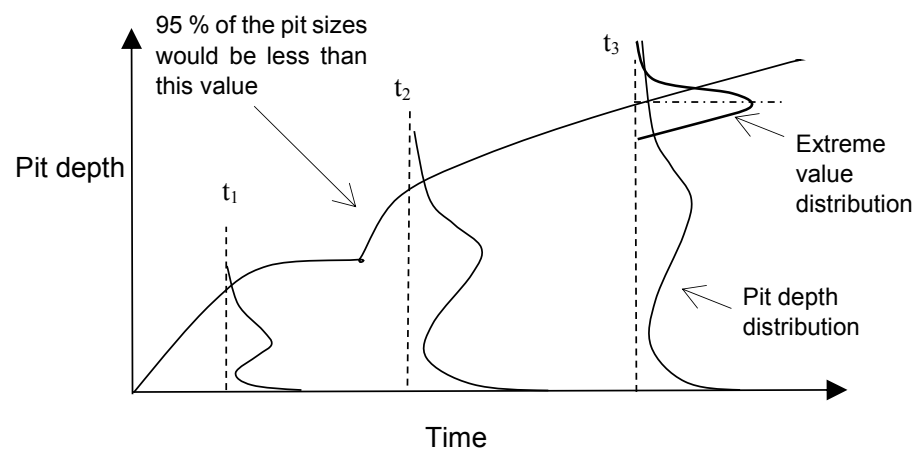

Figure 1: Pit depth distribution over time (see [37], [38] and [39])

Figure 1 shows the pit depth distribution at a selected time. These data are usually used for a small number of extreme value pit depths and give an approximation of the corrosion profile for the dominant pits. When the probability of pit density plot is drawn for all the pits, it has a similar profile but is narrower in the larger extreme tail of the distribution. The probability of density function provides a probability distribution for a discrete random variable (pit dimension data in our case). The probability of the outcomes is equal the area under the curve for a given range of pit depths. The schematic graph in Figure 2 becomes wider as the depth increases over time and there is more variety in the pit depth. According to [38] the increase in the depth variety, which is the distance between minimum and maximum possible depth in each year's plot, increases linearly over time.

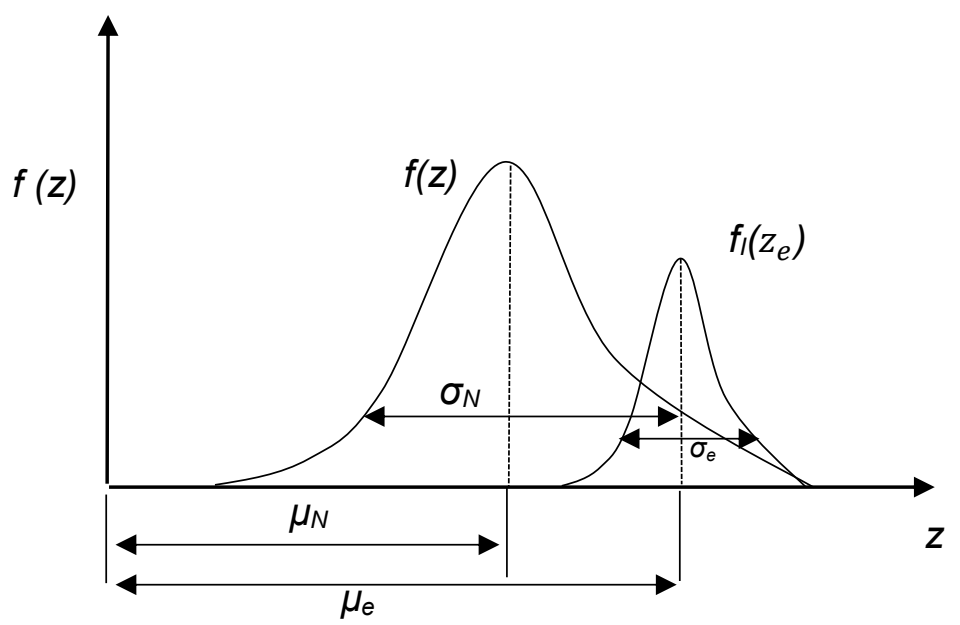

Figure 2: Extreme value distribution of pit depths. $f(z)$ is the probability density function for all the pits and $f\left(z_{e}\right)$ is the extreme probability density function

$f_{I}\left(z_{e}: \mu_{e}, \sigma_{e}\right)=\exp \left(-\exp \left(-\frac{\left(z_{e}-\mu \mathrm{e}\right)}{\sigma_{e}}\right)\right)$ 
$f_{l}\left(z_{e}\right)$ is the extreme probability density function defined in Equation 1. $z_{e}$ is the extreme value pit depth, $\mu_{\mathrm{e}}$ is the location parameter and $\sigma_{e}$ is the scale parameter. The distribution for total depth values can be calculated from the complete population of the pits $(f(z))$ by relating the mean $\left(\mu_{N}\right)$ and standard deviation of the normal distribution $\left(\sigma_{N}\right)$ to the location and scale parameters using the following formulas [38]:

$$
\mu_{e}=\mu_{N} A \sigma_{N}
$$

$$
\sigma_{e}=B \mu_{N}
$$

Equation 3

where

$$
A=\frac{2 \operatorname{Ln} N-0.5 \operatorname{Ln} \operatorname{Ln} N-\operatorname{Ln}(2 \sqrt{N)}}{\sqrt{2 \operatorname{Ln} N}}
$$

Equation 4

and

$$
B=\frac{1}{\sqrt{2 \operatorname{LnN}}}
$$

Equation 5

In Equation 4 and Equation 5, $N$ is the number of pit depth points sampled. In Figure 3, the evolution of mean depth $\left(\mu_{N}\right)$ and the location parameter $\left(\mu_{e}\right)$ for the samples used in [27] are plotted for 180 weeks. The plots clearly show that HAZ is much more vulnerable to pitting.
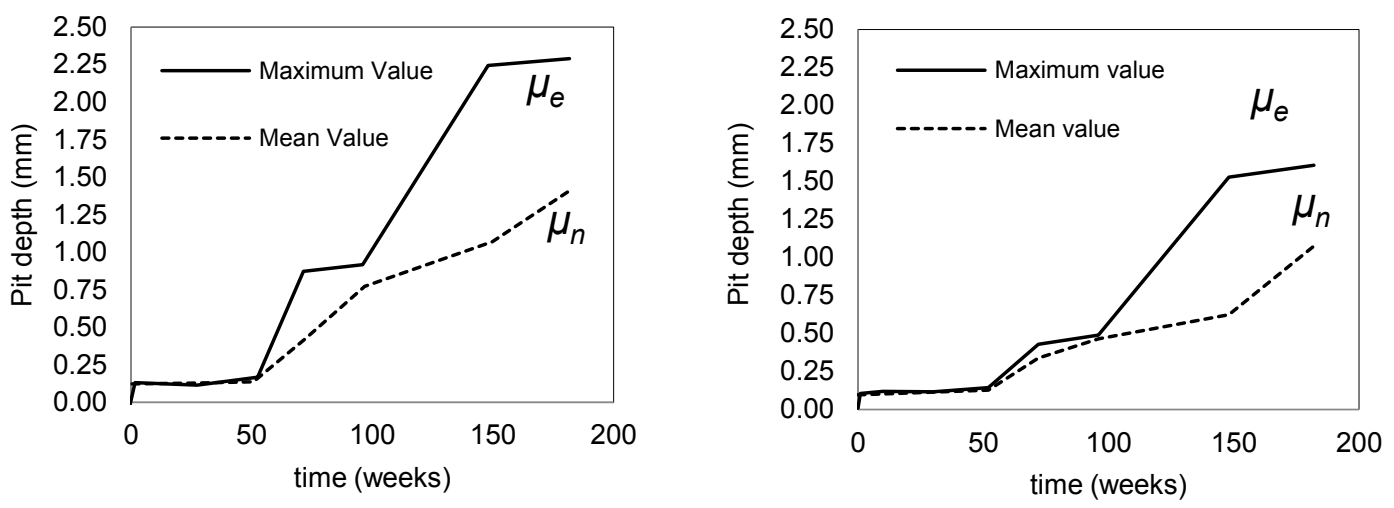

Figure 3: Pit depth mean value and extreme values for HAZ (left) and WM (right) (data from [27])

The following distributions were generated based on the data from [27] and using Equation 1 with a density of $0.012 \mathrm{pits} / \mathrm{mm}^{2}$. Although not shown here for brevity, the analysis showed that similar distributions are generated for the WM and BM while HAZ has shown the largest pits (Figure 4a-d). It is worth noting that this analysis provides approximate pitting profiles and possible crack geometries which initiate from these pits. In the simulations performed in this study, the case for 3.5 years of exposure time is considered as it covers a more diverse pit range and also includes the largest pits. It is not straight forward to define the pitting profile for longer time periods because of 
the stochastic nature of the pitting as well as the general corrosion that can completely change the surface texture. This study aims to provide guidance on the detected pitting crack propagation profile rather than specific time for pit evolution and crack initiation, as corrosion is a very stochastic and time dependent process. Therefore, based on the data available in the literature, the extreme value distribution for year 3.5, the most extreme case, has been considered in this study.
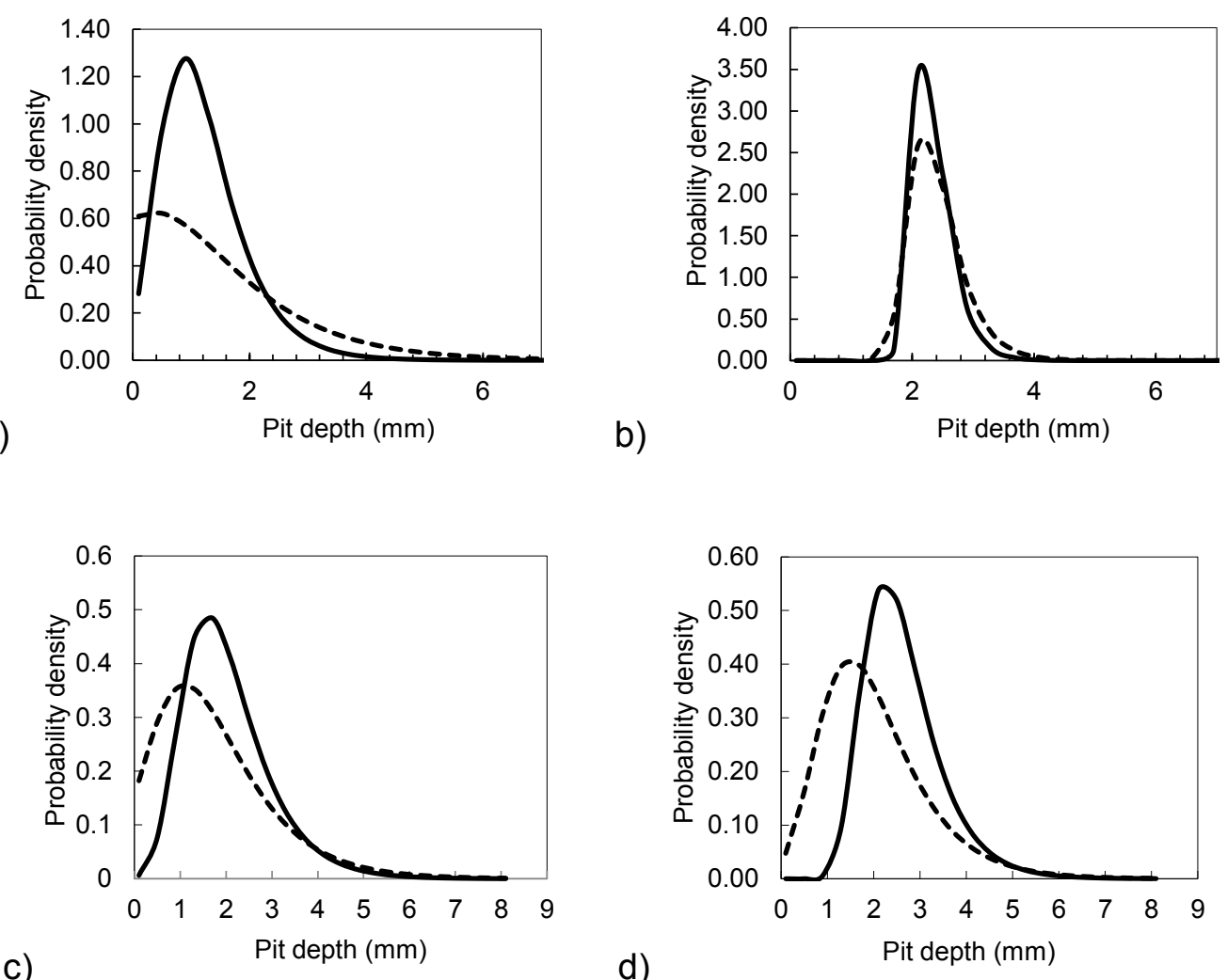

Figure 4: Probability density for pit depths at a) 1.5 years, b) 2 years, c) 3 years and d) 3.5 years times in HAZ for 10 pits (extreme values plotted with solid lines and the dashed line is the distribution of all pits in the sample)

\subsection{General Corrosion Rate}

The effect of general corrosion and material thinning should not be neglected when it comes to corrosion fatigue assessment. A crack initiated from a corrosion pit might not necessarily propagate if the general corrosion exceeds the crack growth rate and physically removes the stress concentration ahead of the pit/crack tip. The corrosion rates in a submerged structure vary depending on the location and the seawater chemical/biological properties. The corrosion rate of steel in different geographical locations are presented in Table 1 [41]. In this table, CP indicates corrosion protection. Moreover, it has been reported in [41] and [42] that the corrosion rate for underwater sections of a steel structure is around $0.2 \mathrm{~mm} /$ year.

Table 1: General corrosion rates at different locations around the world

\begin{tabular}{lcc} 
Location & $\begin{array}{c}\text { Underwater zone } \\
\text { (mm/year) }\end{array}$ & $\begin{array}{c}\text { Splash zone } \\
\text { (mm/year) }\end{array}$ \\
\hline Bay of Tokyo & $0.01(\mathrm{CP})$ & 0.50 \\
England (port facility) & 0.14 & 0.18 \\
Netherlands & 0.06 & 0.18 \\
Cyprus & 0.11 & 0.21 \\
UAE & 0.12 & 0.22 \\
New York & $0.025(\mathrm{CP})$ & 0.15
\end{tabular}


As seen in Table 1, the corrosion rate is much higher in the splash zone than the underwater zone. It should be noted that the corrosion rate may not remain the same over long periods of time. Temperature can accelerate the corrosion process.

The corrosion loss vs. time trends for mild steel at two temperatures of 10 and $20{ }^{\circ} \mathrm{C}$ are shown in Figure 5. The data in Figure 5 is taken from the same location the data for corrosion pit dimensions have been collated [43]. For the current study, corrosion rate of near $0.2 \mathrm{~mm} / \mathrm{year}$ is considered as a reasonable assumption for the North Sea with temperatures near $8-10{ }^{\circ} \mathrm{C}$. For the crack growth rates larger than the general corrosion rate, the crack length is always measured from the initial surface, which is conservative since the material thinning will reduce the crack length and changes the stress intensity factor value, however it must be noted that the stresses in the bulk material increase as a result of thickness reduction. In the present study, no corrosion protection is considered in the analysis to account for the worst-case scenario where the protection/coating is broken and the material is exposed to the seawater.

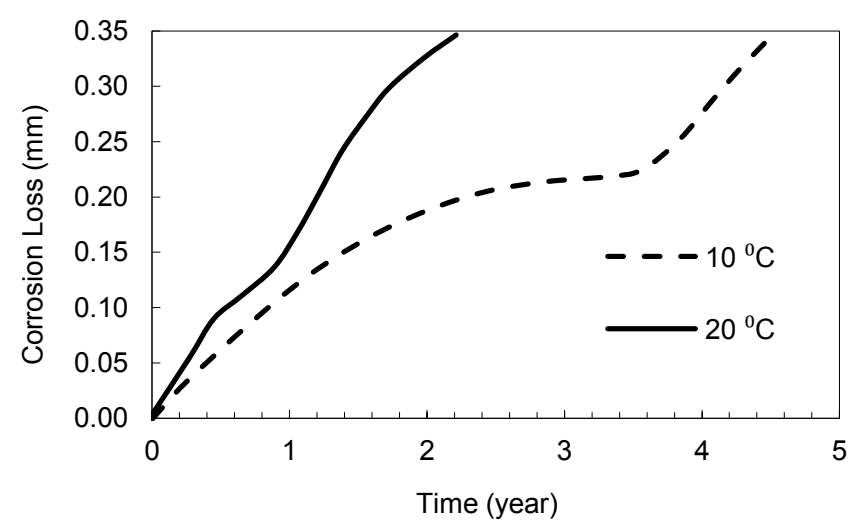

Figure 5: General corrosion rates at different temperatures [43]

\section{Walker Formula for Fatigue Crack Growth Rates at Different R Ratios}

The material used in this study is $\mathbf{S} 355$ structuual steel which is widely used in offshore applications. The Paris law fatigue data on S355 structural steel HAZ material is taken from the SLIC project results for $R=0.1$ for weld joint free corrosion in seawater [44]. As shown later in section 6.1. Quasi-static and cyclic stress analysis, in an offshore floating structure the effective $R$ ratio is much greater than 0.1 and is close to 1. Therefore, adjustments need to be made in the fatigue crack growth power law constants to account for higher $\mathrm{R}$ ratios. For this purpose, the Walker's model is employed to derive the fatigue crack growth power law constants corresponding to higher $\mathrm{R}$ ratios [45]. The Walker's model, which correlated the fatigue crack growth rate $\frac{d a}{d N}$ with the stress intensity factor range $\Delta K$, is shown in Equation 6.

$$
\frac{d a}{d N}=A\left[\frac{\Delta K}{(1-R)^{(1-\gamma)}}\right]^{n}
$$

Equation 6

where $\gamma$ is the parameter which controls the sensitivity to the changes in the $R$ ratio. Following the analysis shown in [22], $\gamma=0.6$ has been considered in this study. The Paris law constants in ABAQUS direct cyclic solver are defined using the energy release rate (see Equation 7), therefore the stress intensity factor range needs to be converted to the energy release rate range for implementation in ABAQUS simulations. 


$$
\frac{d a}{d N}=C[\Delta G]^{m}
$$

For plain strain condition, energy release rate is related to the stress intensity factor via the following formula:

$$
\Delta G=\frac{\Delta K^{2} \cdot\left(1-v^{2}\right)}{E}
$$

Paris law for energy release rate becomes:

$$
\frac{d a}{d N}=A^{*}[\Delta K]^{n}=A^{*}\left(\sqrt{\frac{\Delta G \cdot E}{\left(1-v^{2}\right)}}\right)^{n}=A^{*}\left(\frac{E}{\left(1-v^{2}\right)}\right)^{\frac{n}{2}}(\Delta G)^{\frac{n}{2}}
$$

$A^{*}$ is the modified Paris law constant for each $R$ value (Equation 6 ). $\mathrm{C}$ and $\mathrm{m}$ can be calculated as:

$$
\begin{aligned}
A^{*} & =A\left[\frac{1}{(1-R)^{(1-\gamma)}}\right]^{n} \\
m & =\frac{n}{2} \\
C & =A^{*}\left(\frac{E}{\left(1-v^{2}\right)}\right)^{m}
\end{aligned}
$$

The values of Paris law constants, based on both $K$ and $G$ definitions, are calculated for a wide range of $R$ ratios using the Walker's model and are summarized in in Table 2. Moreover, the fatigue crack growth rate correlation with $\Delta K$ for $R$ ratios of $0.1,0.5$ and 0.9 are demonstrated in Figure 6 . In the implementation of the power law constants in ABAQUS simulations it has been assumed that the critical stress intensity factor is $17643.9 \mathrm{MPa} \sqrt{\mathrm{mm}}\left(\mathrm{G}_{I C}=1349 \mathrm{MPa} \mathrm{mm}\right)$ for all $R$ ratios [46].

Table 2: Paris law constants for different $R$ ratios.

\begin{tabular}{ccccc}
\hline$R$ & $A^{*}(\mathrm{HAZ})$ & $n$ (HAZ) & $C$ (HAZ) & $m$ (HAZ) \\
\hline 0 & $7.84 \mathrm{E}-14$ & 3.23 & $3.60 \mathrm{E}-05$ & 1.615 \\
0.1 & $8.99 \mathrm{E}-14$ & 3.23 & $4.12 \mathrm{E}-05$ & 1.615 \\
0.5 & $1.92 \mathrm{E}-13$ & 3.23 & $8.81 \mathrm{E}-05$ & 1.615 \\
0.9 & $1.54 \mathrm{E}-12$ & 3.23 & $7.05 \mathrm{E}-04$ & 1.615
\end{tabular}




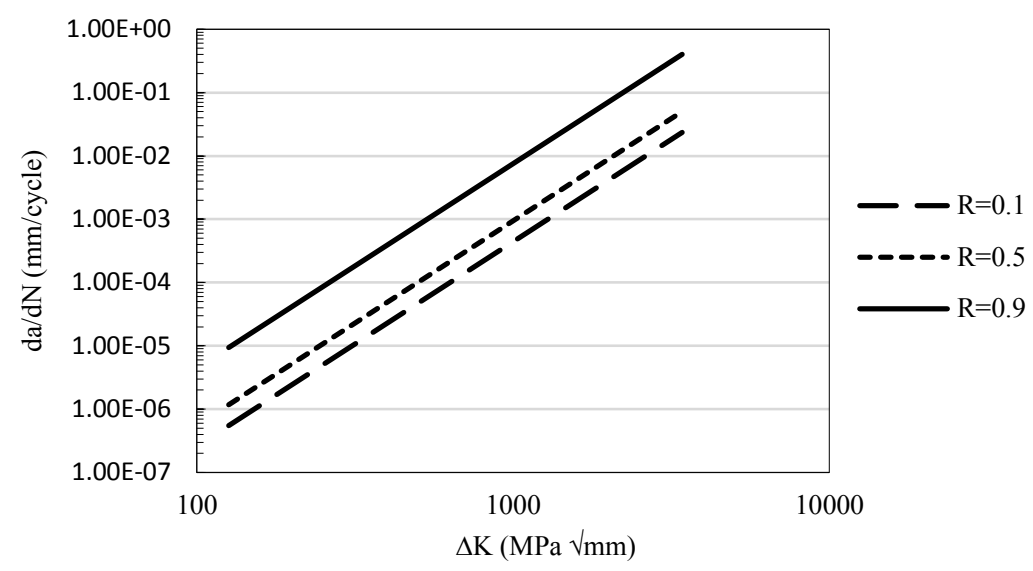

Figure 6: Effect of R-ratio on the fatigue crack growth rate

Although Figure 6 shows that for a given value of $\Delta K$ the crack growth rate increases as the $R$ ratio increases, the obtained trends from the Walker's model can be conservative as some researchers have shown little or no sensitivity to $R$ ratios in the observed fatigue crack growth trends. For example, Jesus et al. [47] carried out experiments on S355 and S690 steel grades to examine the effect of the $R$ ratio on fatigue crack growth and their result show that the fatigue crack growth power law constants are similar for the tests with positive, non-zero $R$ ratios. It must be noted that the crack initiation and fatigue threshold are not considered in the present study. Assuming zero stress intensity factor range threshold is consistent with the recommendations in the BS7910 standard for marine structures, although this recommendation may make the analysis very conservative.

\section{Numerical Implementation}

\subsection{CAD design of the mooring point}

In this study, the floating offshore wind turbine structure of interest is 'OC3-Hywind' spar-buoy platform for 5MW NREL [48]. The turbine specifications are reported in Table 3: Mooring system dimensions (SWL represents the seawater level). These dimensions are used for the dynamic simulation of the model depicted in Figure 7.

Table 3: Mooring system dimensions (SWL represents the seawater level)

\begin{tabular}{|l|c|}
\hline Number of mooring lines & 3 \\
\hline Depth to anchors below SWL (m) & 320 \\
\hline Depth to fairleads below SWL (m) & 70 \\
\hline Radius to anchor from platform centre (m) & 853 \\
\hline Radius to fairleads from platform centreline (m) & 5.2 \\
\hline Mooring line length (m) & 902 \\
\hline
\end{tabular}




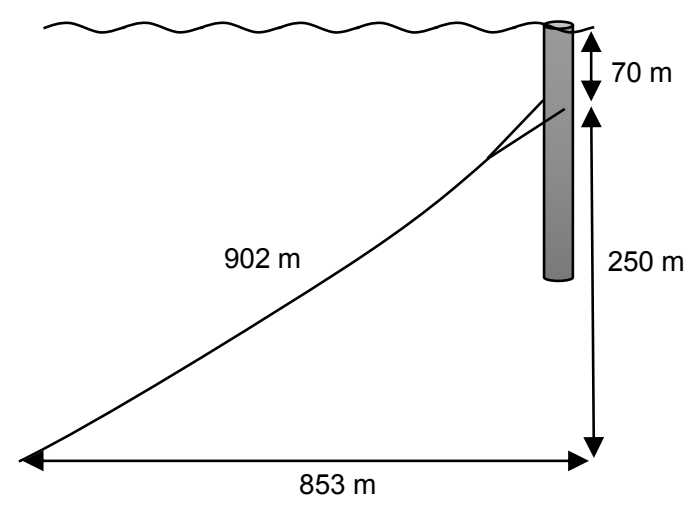

Figure 7: Dimensions of the mooring lines

The mooring lines are assumed to have been connected to the foundation in a star-shape arrangement (Figure 8a). The upper part of the mooring line consists of a double set of bridle chains connected to the main line through a tri-plate [49]. The bridle length is $50 \mathrm{~m}$ and the approximate angles used for the load calculations are depicted Figure $8 \mathrm{~b}$. The inclination of the tower is considered in the load calculations while the loads in individual mooring lines is considered equal. Each mooring point is connected to two bridles using the mechanism shown in Figure 9.

a)

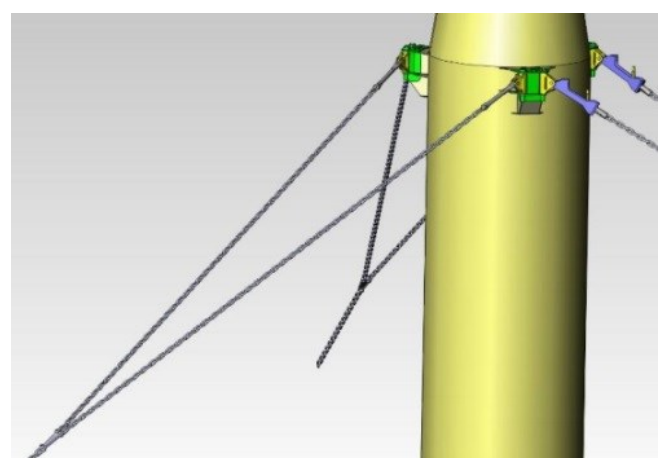

b)

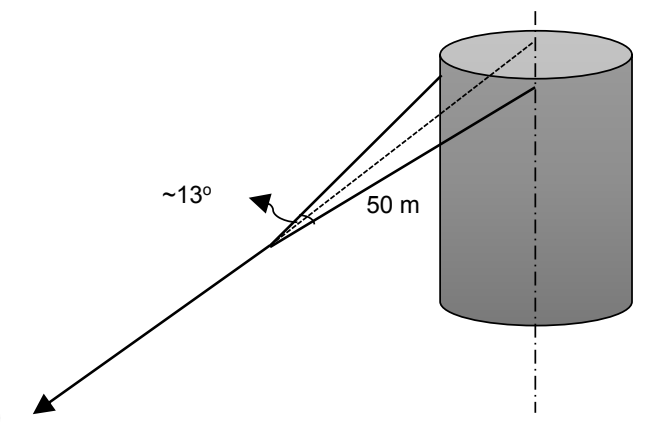

Figure 8: (a) Mooring lines connected to the foundation in star shape. (b) Mooring line configuration taken from [50] 


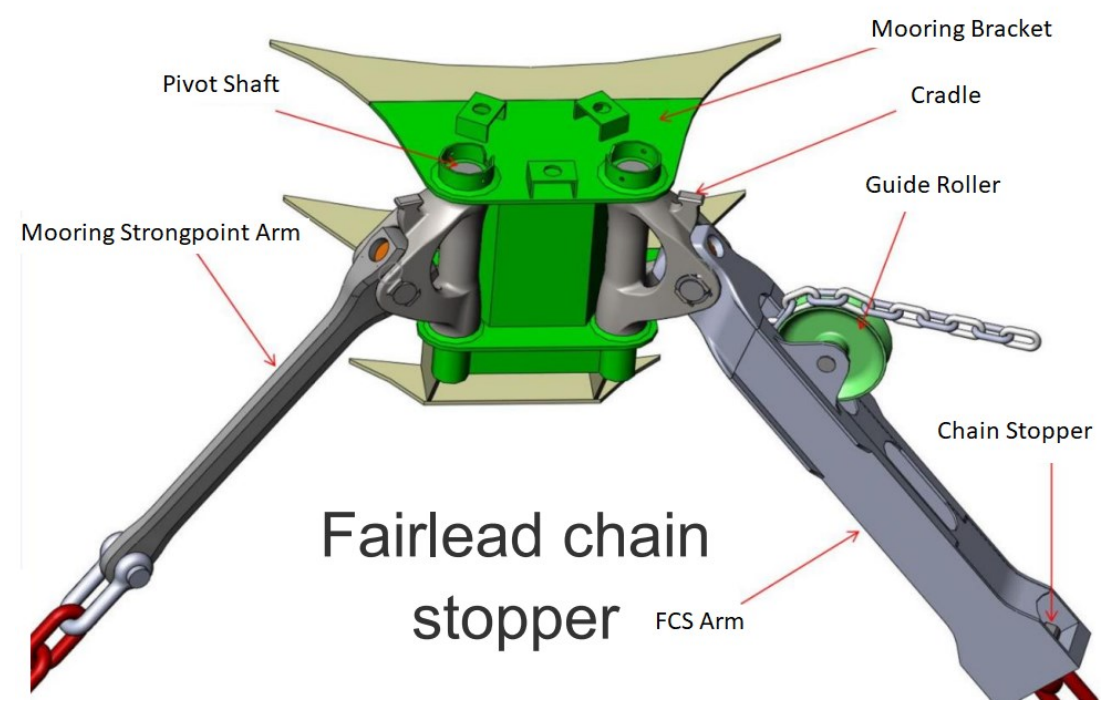

Figure 9: Mooring system for Hywind Scotland (taken from [50])

The mooring lines have 120 degrees angle between them. For the purpose of numerical simulations in this study, a single mooring line has been considered and its intersection point with the floating foundation is modelled in ABAQUS (see Figure 10). As seen in this figure (Figure 10), the partitions of the foundation are large enough to minimize the effect of the boundary conditions on the mooring point stresses. The mooring point is back-engineered from Oc3-Hywind, assuming that $30 \mathrm{~mm}$ welded plates are used in this part of the structure.

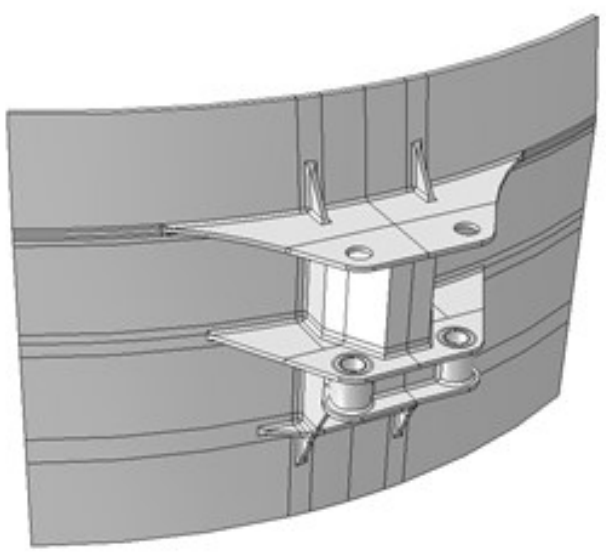

Figure 10: CAD drawing for the mooring line intersection point with the foundation

It is worth noting that the main focus of this study is the weldment at the mooring line intersection point with the floating structure and not the foundation body itself. The weld geometry is created in abaqus with a $45^{\circ}$ fillet and the weld leg equals half the plate thickness. For the weld toe radius, a conservative approach is considered here by choosing 0.0 radius (sharp corner) which has the maximum stress magnification effect. The mooring loads are transmitted onto the mooring points via cradles, which are pinned onto the mooring points. The pin connection is simulated using the equation constraint feature in ABAQUS such that it only sustains horizontal loads perpendicular to the defined planes around the pins and the vertical loads are applied to the surface on which that cradle sits (see

Figure 11). 


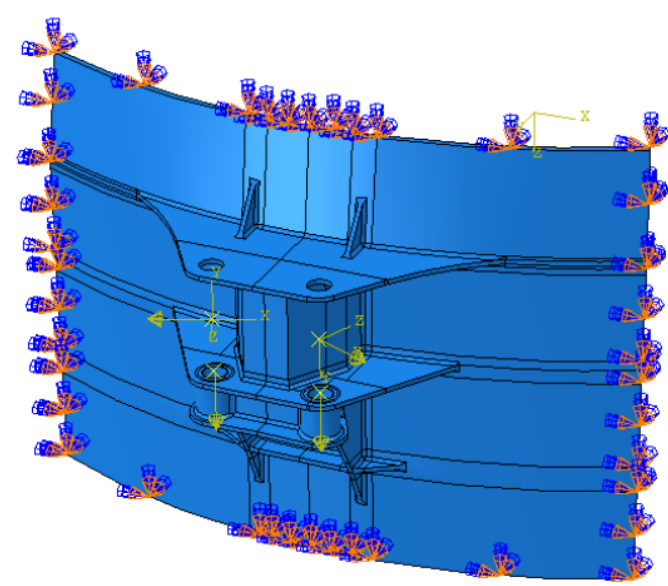

a)

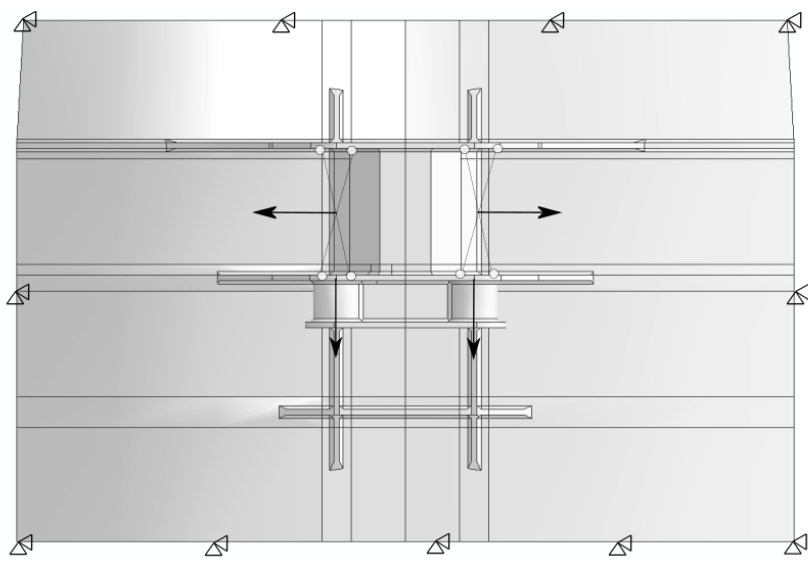

b)

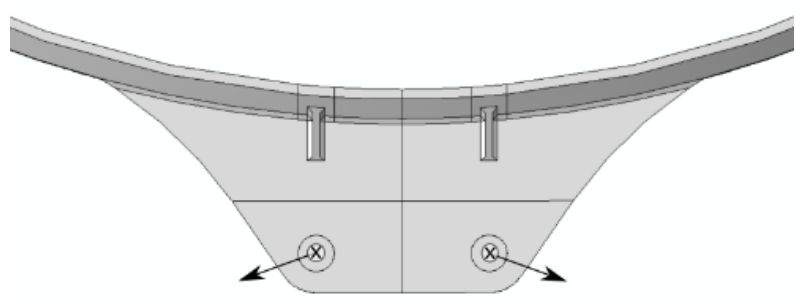

c)

Figure 11: Loads and equation constraints for the fairlead connection. a) The horizontal load is sustained by the inner surface of the holes where the pin is inserted. b) Front and c) top view of the mooring point loads.

\subsection{Mooring line forces and cyclic load calculations}

The mooring line forces and cyclic loads applied on the floating offshore wind turbine are obtained from simulations carried out in MoorDyne and FAST [20] for 11 wind speeds (between 4 and $24 \mathrm{~m} / \mathrm{s}$ ) and 6 different wave inputs, summing up to 66 combinations in total. The outputs are the three components of load $\left(f_{x}, f_{y}, f_{z}\right)$ in every mooring line over a time period of around 10 minutes each. The effect of the inclination and movement of the structure is considered in the decomposition of the loads. For simplicity, the loads in bridles that are connected to the same mooring line are considered equal. Figure 12 shows an example of the mooring line load distribution over time at $12 \mathrm{~m} / \mathrm{s}$ wind speed for one wave inputs (There are six different wave inputs for each wind speed simulation). As seen in this figure, the highest load is experienced in one of the mooring lines (line 1, Figure 12), whereas the other two predicted forces fall close to or upon each other with lower magnitudes. When the turbine foundation is moved away from one mooring line, the load in that line increases and the other two decrease. For each cyclic load, this appears as 180 degrees phase shift between the loads in the first line (with the higher load) and the other two loads. Another interesting observation in this figure is that the load data can be mathematically related to each other. They mirror each other but with different amplitude and mean values. This is a useful observation to note since it allows the cycle counts to be done only on one of the loads and the other two mooring lines cyclic loads can be calculated from the first counted data. 


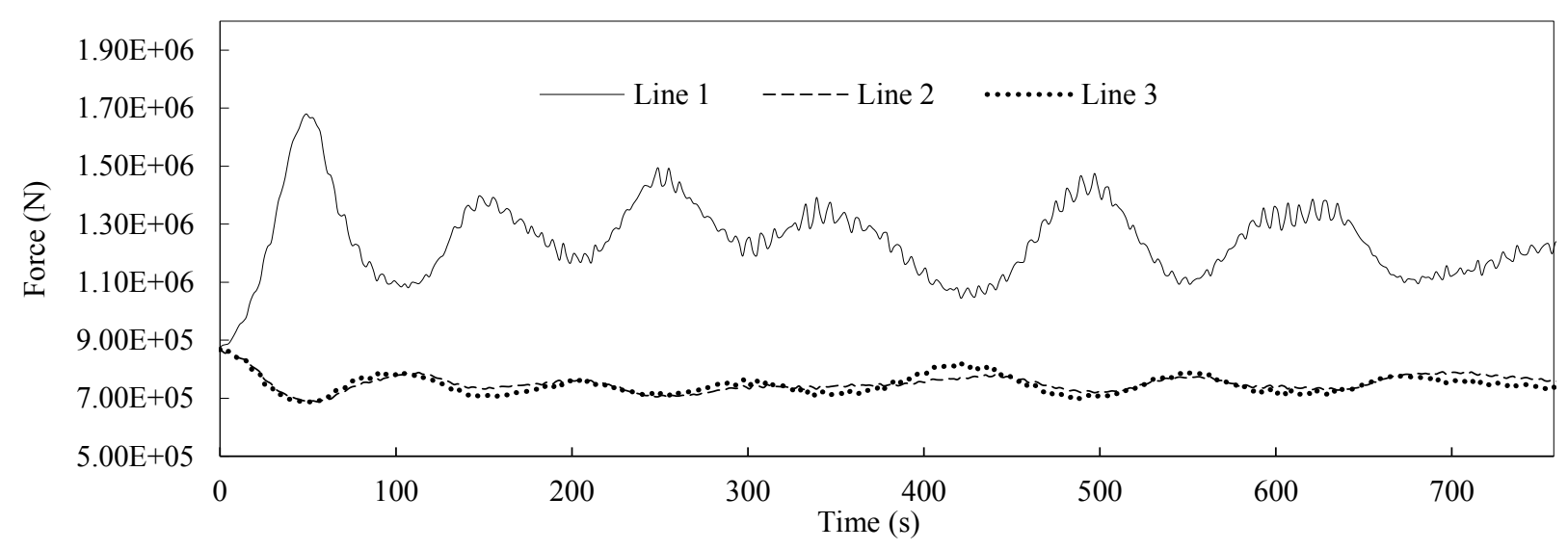

Figure 12: An example of mooring line forces for $12 \mathrm{~m} / \mathrm{s}$ wind speed at each line

\subsection{Rainflow-cycle count}

The Rainflow cycle counting technique was developed by Matsuishi and Endo [51] to deal with varying cyclic stresses in fatigue analysis. For the loads in the present study, it is possible to apply Rainflow cycle counting on the loads since a distinct load case and corresponding frequency is applied at a moment in time. This is due to the fact that the loads in mooring lines are proportional and mirror each other; so for each specific cyclic load in one mooring line, there are unique responses in the other two mooring lines with the same frequencies. This characteristic makes the numerical implementation possible in ABAQUS direct cyclic solver as all the applied loads have similar frequencies, hence the energy release rate is measured at the maximum and minimum of the resultant cyclic stresses.

The cycle count was performed on the mooring force with the largest magnitude. The probability of each wind speed occurrence is different during a one-year period (Figure 13). To find out the contribution of each wind speed to the cycle count, Rainflow counting was carried out on each speed sample separately. The number of cycles per unit time was then calculated for each identified load cycle and multiplied by the probability of the wind speed (summing up to $100 \%$ of operational time). After identifying all the cycles and the number of repeat times, similar load cycles were combined into the same category in order to group the loads into fewer sets. Finally, 18 sets of load cycles were created.

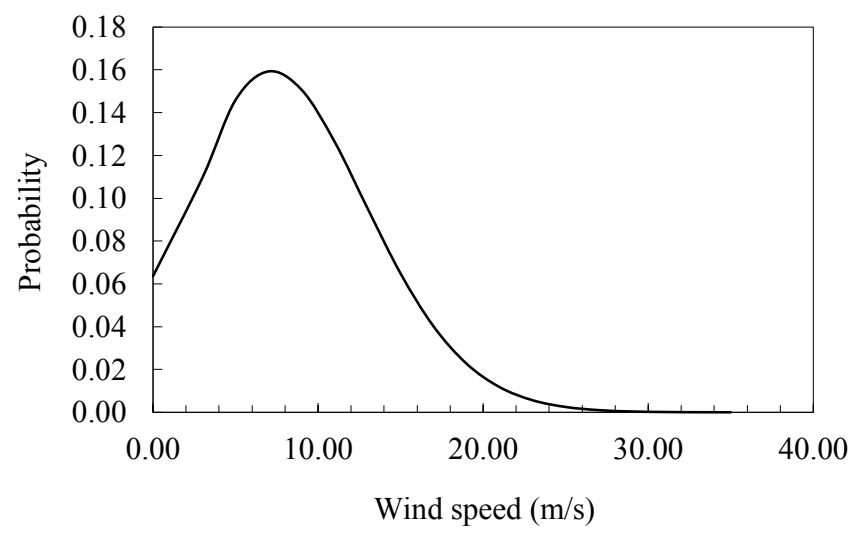

Figure 13: The probability distribution of wind speed

As seen in Figure 14, two fairleads are connected to each mooring point. Line 1 with the highest load (as explained in 5.2. Mooring line forces and cyclic load calculations) is split into two equal loads (A) and line 2 and 3 apply load $B$ via each bridle. For each load case the relevant component of the load is applied. In Table 4, all the cyclic loads that are applied to the mooring points are presented. This 
This is a peer-reviewed, accepted author manuscript of the following article: Moghaddam, B. T., Hamedany, A. M., Taylor, J., Mehmanparast, A., Brennan, F., Davies, C. M., \& Nikbin, K. (2020). Structural integrity assessment of floating offshore wind turbine support structures. Ocean Engineering, 208, [107487]. https://doi.org/10.1016/j.oceaneng.2020.107487

table has the horizontal and vertical load component of each bridle. Figure 15shows an example of the horizontal loads applied on pin A and B over 18 steps. As seen in this figure, at each step, two horizontal loads ( $A$ and $B$ ) are applied to the reference points which are constrained to the corresponding surfaces (see

Figure 11) for the horizontal loads. Same arrangement applies to the vertical loads. In total, 4 cyclic loads (with the same frequencies) are applied to 4 reference points at each step. For the consecutive step, the loads are updated and applied in the same manner. Each load set must be applied over its corresponding number of cycles shown in Table 4.

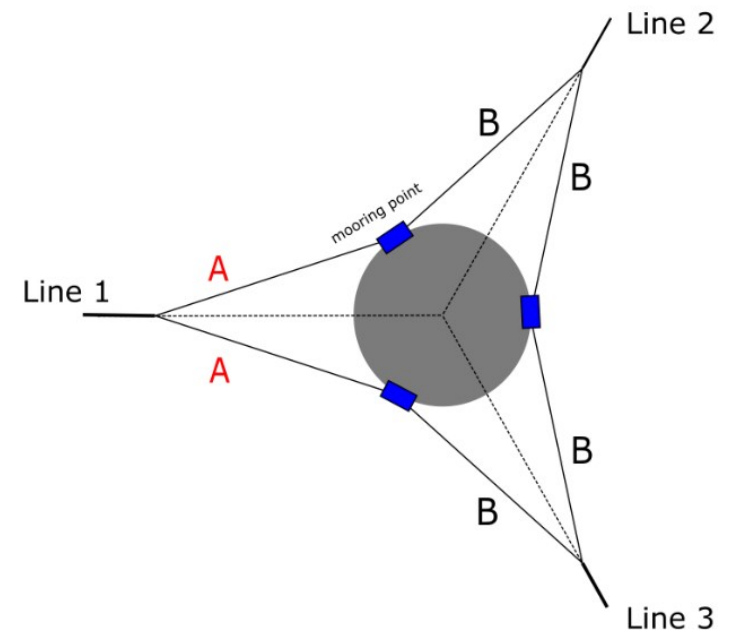

Figure 14 Line 1 has the largest force. The two other lines have almost similar loads. A and B are bridles connecting the mooring lines to the mooring point in star shape

Table 4: All cyclic forces $(N)$ in bridle type $A$ and $B$

\begin{tabular}{cccc|c|c|c|c|c|cc|}
\cline { 2 - 9 } \multicolumn{1}{c|}{} & \multicolumn{2}{c}{ A (horizontal) } & \multicolumn{2}{c|}{ A (vertical) } & \multicolumn{2}{c|}{ B (Horizontal) } & \multicolumn{2}{c|}{ B (vertical) } & \\
\hline step & mean & amplitude & mean & amplitude & mean & amplitude & mean & amplitude & cycle/year \\
\hline 1 & $4.25 \mathrm{E}+05$ & $1.25 \mathrm{E}+04$ & $-2.86 \mathrm{E}+05$ & $4.17 \mathrm{E}+03$ & $3.25 \mathrm{E}+05$ & $4.17 \mathrm{E}+03$ & $-2.53 \mathrm{E}+05$ & $1.39 \mathrm{E}+03$ & $7.10 \mathrm{E}+05$ \\
2 & $4.95 \mathrm{E}+05$ & $1.25 \mathrm{E}+04$ & $-3.09 \mathrm{E}+05$ & $4.17 \mathrm{E}+03$ & $3.02 \mathrm{E}+05$ & $4.17 \mathrm{E}+03$ & $-2.45 \mathrm{E}+05$ & $1.39 \mathrm{E}+03$ & $9.12 \mathrm{E}+05$ \\
3 & $5.55 \mathrm{E}+05$ & $1.25 \mathrm{E}+04$ & $-3.29 \mathrm{E}+05$ & $4.17 \mathrm{E}+03$ & $2.82 \mathrm{E}+05$ & $4.17 \mathrm{E}+03$ & $-2.38 \mathrm{E}+05$ & $1.39 \mathrm{E}+03$ & $6.58 \mathrm{E}+05$ \\
4 & $6.40 \mathrm{E}+05$ & $1.25 \mathrm{E}+04$ & $-3.58 \mathrm{E}+05$ & $4.17 \mathrm{E}+03$ & $2.53 \mathrm{E}+05$ & $4.17 \mathrm{E}+03$ & $-2.29 \mathrm{E}+05$ & $1.39 \mathrm{E}+03$ & $3.06 \mathrm{E}+05$ \\
5 & $4.30 \mathrm{E}+05$ & $3.25 \mathrm{E}+04$ & $-2.88 \mathrm{E}+05$ & $1.08 \mathrm{E}+04$ & $3.23 \mathrm{E}+05$ & $1.08 \mathrm{E}+04$ & $-2.52 \mathrm{E}+05$ & $3.61 \mathrm{E}+03$ & $1.93 \mathrm{E}+04$ \\
6 & $4.60 \mathrm{E}+05$ & $3.25 \mathrm{E}+04$ & $-2.98 \mathrm{E}+05$ & $1.08 \mathrm{E}+04$ & $3.13 \mathrm{E}+05$ & $1.08 \mathrm{E}+04$ & $-2.49 \mathrm{E}+05$ & $3.61 \mathrm{E}+03$ & $2.45 \mathrm{E}+04$ \\
7 & $5.05 \mathrm{E}+05$ & $3.25 \mathrm{E}+04$ & $-3.13 \mathrm{E}+05$ & $1.08 \mathrm{E}+04$ & $2.98 \mathrm{E}+05$ & $1.08 \mathrm{E}+04$ & $-2.44 \mathrm{E}+05$ & $3.61 \mathrm{E}+03$ & $2.26 \mathrm{E}+04$ \\
8 & $4.00 \mathrm{E}+05$ & $8.00 \mathrm{E}+04$ & $-2.78 \mathrm{E}+05$ & $2.67 \mathrm{E}+04$ & $3.33 \mathrm{E}+05$ & $2.67 \mathrm{E}+04$ & $-2.55 \mathrm{E}+05$ & $8.89 \mathrm{E}+03$ & $1.97 \mathrm{E}+04$ \\
9 & $4.50 \mathrm{E}+05$ & $8.00 \mathrm{E}+04$ & $-2.94 \mathrm{E}+05$ & $2.67 \mathrm{E}+04$ & $3.17 \mathrm{E}+05$ & $2.67 \mathrm{E}+04$ & $-2.50 \mathrm{E}+05$ & $8.89 \mathrm{E}+03$ & $2.48 \mathrm{E}+04$ \\
10 & $4.90 \mathrm{E}+05$ & $8.00 \mathrm{E}+04$ & $-3.08 \mathrm{E}+05$ & $2.67 \mathrm{E}+04$ & $3.03 \mathrm{E}+05$ & $2.67 \mathrm{E}+04$ & $-2.45 \mathrm{E}+05$ & $8.89 \mathrm{E}+03$ & $2.90 \mathrm{E}+04$ \\
11 & $5.60 \mathrm{E}+05$ & $8.00 \mathrm{E}+04$ & $-3.31 \mathrm{E}+05$ & $2.67 \mathrm{E}+04$ & $2.80 \mathrm{E}+05$ & $2.67 \mathrm{E}+04$ & $-2.38 \mathrm{E}+05$ & $8.89 \mathrm{E}+03$ & $3.84 \mathrm{E}+04$ \\
12 & $4.90 \mathrm{E}+05$ & $1.20 \mathrm{E}+05$ & $-3.08 \mathrm{E}+05$ & $4.00 \mathrm{E}+04$ & $3.03 \mathrm{E}+05$ & $4.00 \mathrm{E}+04$ & $-2.45 \mathrm{E}+05$ & $1.33 \mathrm{E}+04$ & $2.80 \mathrm{E}+04$ \\
13 & $5.60 \mathrm{E}+05$ & $1.20 \mathrm{E}+05$ & $-3.31 \mathrm{E}+05$ & $4.00 \mathrm{E}+04$ & $2.80 \mathrm{E}+05$ & $4.00 \mathrm{E}+04$ & $-2.38 \mathrm{E}+05$ & $1.33 \mathrm{E}+04$ & $2.21 \mathrm{E}+04$ \\
14 & $4.90 \mathrm{E}+05$ & $1.95 \mathrm{E}+05$ & $-3.08 \mathrm{E}+05$ & $6.50 \mathrm{E}+04$ & $3.03 \mathrm{E}+05$ & $6.50 \mathrm{E}+04$ & $-2.45 \mathrm{E}+05$ & $2.17 \mathrm{E}+04$ & $1.87 \mathrm{E}+04$ \\
15 & $5.60 \mathrm{E}+05$ & $1.95 \mathrm{E}+05$ & $-3.31 \mathrm{E}+05$ & $6.50 \mathrm{E}+04$ & $2.80 \mathrm{E}+05$ & $6.50 \mathrm{E}+04$ & $-2.38 \mathrm{E}+05$ & $2.17 \mathrm{E}+04$ & $2.95 \mathrm{E}+04$ \\
16 & $4.90 \mathrm{E}+05$ & $2.90 \mathrm{E}+05$ & $-3.08 \mathrm{E}+05$ & $9.67 \mathrm{E}+04$ & $3.03 \mathrm{E}+05$ & $9.67 \mathrm{E}+04$ & $-2.45 \mathrm{E}+05$ & $3.22 \mathrm{E}+04$ & $1.20 \mathrm{E}+04$
\end{tabular}


This is a peer-reviewed, accepted author manuscript of the following article: Moghaddam, B. T., Hamedany, A. M., Taylor, J., Mehmanparast, A., Brennan, F., Davies, C. M., \& Nikbin, K. (2020). Structural integrity assessment of floating offshore wind turbine support structures. Ocean Engineering, 208, [107487]. https://doi.org/10.1016/j.oceaneng.2020.107487

$\begin{array}{llllllllll}17 & 5.60 \mathrm{E}+05 & 2.90 \mathrm{E}+05 & -3.31 \mathrm{E}+05 & 9.67 \mathrm{E}+04 & 2.80 \mathrm{E}+05 & 9.67 \mathrm{E}+04 & -2.38 \mathrm{E}+05 & 3.22 \mathrm{E}+04 & 2.13 \mathrm{E}+04 \\ 18 & 5.60 \mathrm{E}+05 & 3.80 \mathrm{E}+05 & -3.31 \mathrm{E}+05 & 1.27 \mathrm{E}+05 & 2.80 \mathrm{E}+05 & 1.27 \mathrm{E}+05 & -2.38 \mathrm{E}+05 & 4.22 \mathrm{E}+04 & 1.19 \mathrm{E}+04\end{array}$

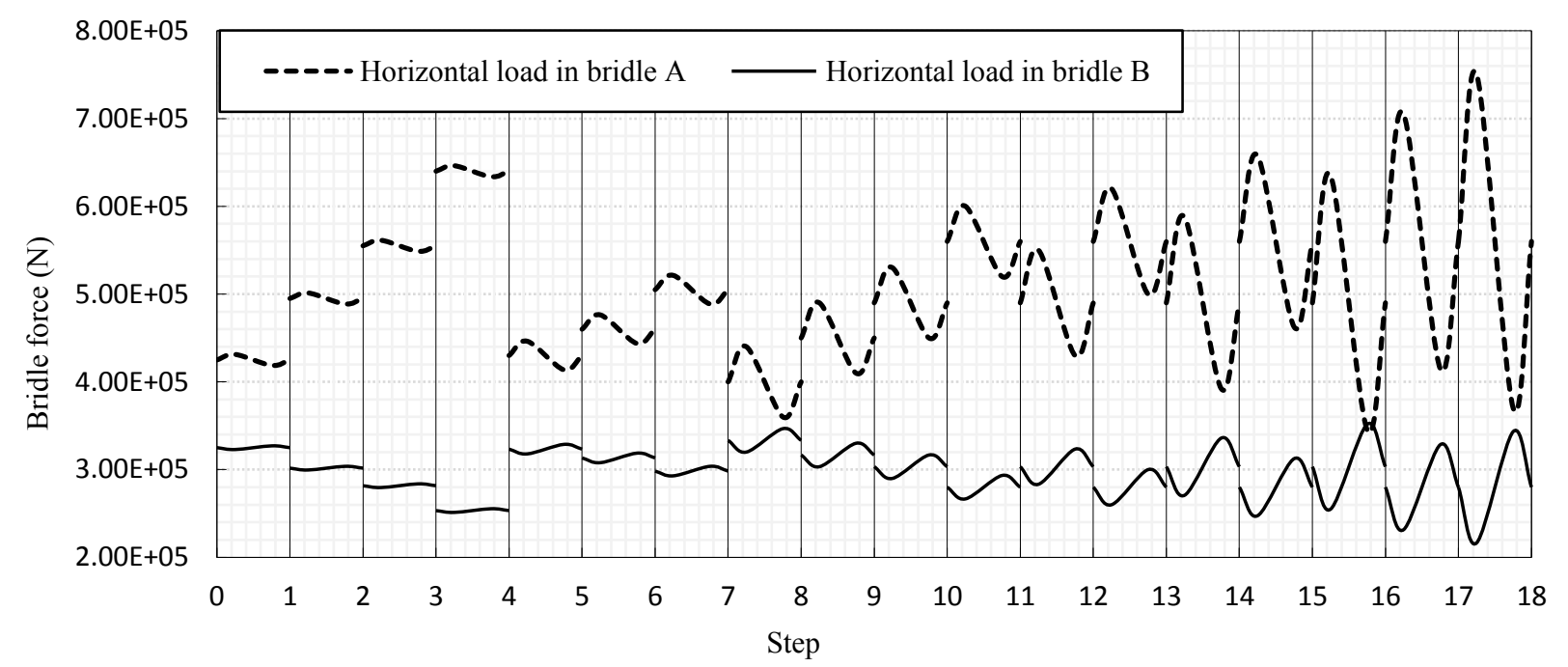

Figure 15: A and B load cycles for all 18 cases (only horizontal component is plotted).

All possible load combinations on a mooring point are A-B, B-B, and B-A depending on the wind direction. Figure 16 shows the yearly distribution of wind direction probability for the North Sea regardless of the wind speed.

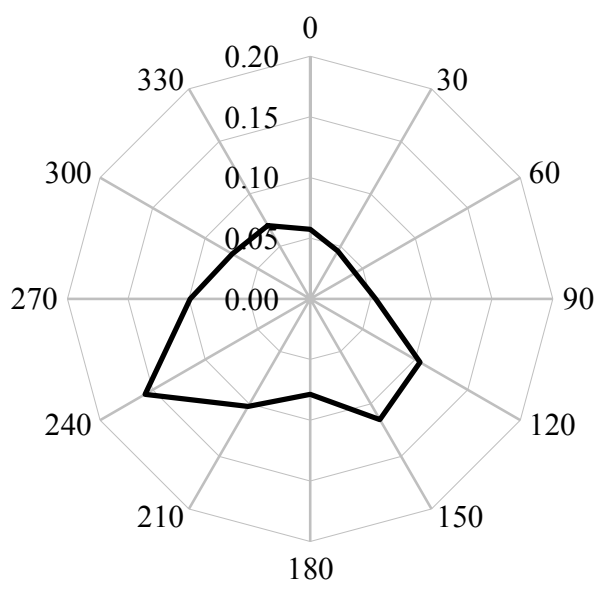

Figure 16: Wind direction probability for all wind speed combined

Considering the distribution of wind directions for the North Sea, it appears that almost two thirds of the time the wind points towards one direction (210 degrees approximately). The following arrangement can approximately describe all possible loading combinations at a mooring point during a year; $67 \%$ A-B, $16.5 \%$ B-B, $16.5 \%$ B-A. For the other two mooring points, one will completely mirror A-B (i.e. BA) and the other mooring point will experience $B-B$ load for $67 \%$ of the time, which is not severe since the loads in group $B$ are much lower. Since the maximum stress location/magnitude changes when A$B$ is switched to $B-A$ or $B-B$, a conservative approach was chosen here by considering only one arrangement $(A-B)$ for $100 \%$ of the time. The load cases are applied in 18 different steps in ABAQUS 
direct cyclic solver. If all arrangements were considered, all the 18 steps have to be repeated for each three cases. The simulation can be done for the entire time span of interest or repeated in order to apply all the cycles evenly throughout the time.

Another interesting outcome of the load analysis is to identify the load frequencies. Table 5 shows the approximate value for each of the load frequencies considered in the analysis. In this table, f1 and f2 are the two observed frequencies in the load. As seen in this table, there are two major cycles with a high frequency of around $0.15-0.3 \mathrm{~Hz}$ and a smaller one with the frequency of around $0.01-0.02 \mathrm{~Hz}$

Table 5: Approximate load frequencies in the mooring line loads

\begin{tabular}{ccc}
$\begin{array}{c}\text { Wind speed } \\
(\mathrm{m} / \mathrm{s})\end{array}$ & $\mathrm{f} 1(\mathrm{~Hz})$ & $\mathrm{f} 2(\mathrm{~Hz})$ \\
\hline 4 & 0.14 & 0.01 \\
8 & 0.28 & 0.02 \\
12 & 0.25 & 0.02 \\
16 & 0.28 & 0.02 \\
20 & 0.22 & 0.01 \\
24 & 0.25 & 0.02
\end{tabular}

\subsection{Pit generator script}

A Python script is developed and employed to generate the corrosion pit geometries using the extreme value distribution. Based on the results in section 3.1. Pit depth and density distribution, the pit dimensions have a non-uniform distribution. The developed script first chooses a desired number of pit sizes from an array with possible depths within the pre-defined range. In order to create the non-uniform distribution, the sizes with higher probability are repeated more times according to the probability distribution shown in Figure 17.

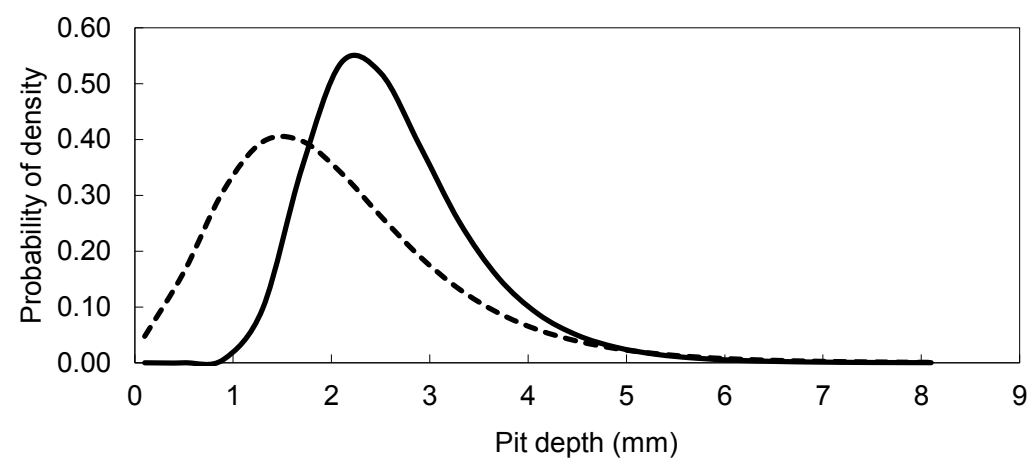

a)

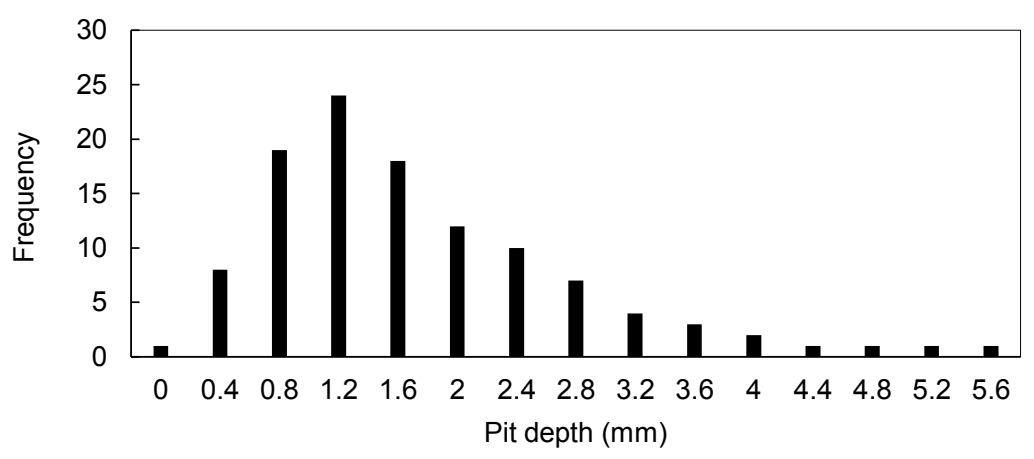

b) 
This is a peer-reviewed, accepted author manuscript of the following article: Moghaddam, B. T., Hamedany, A. M., Taylor, J., Mehmanparast, A., Brennan, F., Davies, C. M., \& Nikbin, K. (2020). Structural integrity assessment of floating offshore wind turbine support structures. Ocean Engineering, 208, [107487]. https://doi.org/10.1016/j.oceaneng.2020.107487

Figure 17: Corrosion pit non-uniform probability distribution: a) the probability density distribution b) array of discretized sizes, with pit depths with higher probability repeated more times according to the probability density distribution.

The crack width is calculated based on the crack length, by multiplying the depth by a number between 1 and 2 (i.e. aspect ratio), again with a non-uniform distribution with tendency towards larger values as the time passes (i.e. flatter ellipses). This distribution is approximated by relating the mass loss (general corrosion) to the pit depth and calculating the radius from the pit volume at different times. The following assumptions have been made in order to generate random pits in this work:

- The pit profile becomes wider as time passes (particularly in modern steels). The aspect ratio for the pits is randomly selected from a non-uniform distribution to increase the radius-to-depth ratio over time. This ratio is often between 1 and 2 [33].

- The pit dimensions are selected randomly from an array (which is selected according to the pit probability distribution density) of possible depths. This means that only a finite set of dimensions exists and the size range is not continuous (only the sizes shown in Figure 17 can be selected).

- Only absolute pit depths, from the intact surface to the bottom of the pit, are considered in the analysis.

It is worth noting that the area chosen for the simulation must be large enough to create enough pits that represent that year's corrosion pitting profile. In the simulations performed in this study, the point in time with the largest pits was examined (i.e. 3.5 years of corrosion) to account for the worst-case scenario.

\subsection{Direct cyclic solver and crack growth implementation}

ABAQUS direct cyclic solver, which is a quasi-static analysis that uses Fourier series to find the stabilized cyclic response of a structure under the applied cyclic loading condition, has been employed in crack growth simulations. The cracks from corrosion pits are defined explicitly using extended finite element method (XFEM). The solver applies one cyclic load at a defined step and finds the stabilized response of the structure iteratively in the form of a Fourier series. When the stabilized state is achieved, the change in the energy release rates between the maximum and minimum cyclic loads, $\Delta G$, is calculated. The $\Delta G$ approach is used in the form of the Paris law to find the number of cycles needed to advance the crack by breaking through the weakest element at the crack tip zone. In this way, computational time is saved by skipping the cycles between crack growth steps [52].

Several direct cyclic analysis steps can be employed in the analysis, which will allow application of different cyclic loads. Each cyclic load case is defined from the result of Rainflow cycle counting, detailed in section 5.3. Rainflow-cycle count. The cyclic load cases here have four components, which are applied onto four reference points to exert horizontal and vertical forces on each bridle. In the present study the loads in the mooring lines are almost synchronized and the cycle count can be done on the loads instead of the stresses. In other words, the stress cycles follow the same frequency as the external loads.

\subsection{XFEM Crack set up}

The crack discontinuities are modelled in ABAQUS using extended finite element method (XFEM). When multiple cracks are present, separate cells must be defined for each individual crack. The cracks can grow independently and in case they reach the next cell, they can extend to the new cell and even collide with another crack. The cracks are defined in the form of elliptical surfaces, which are generated by the python script, the details of which was explained in section 5.4. Pit generator script. The crack is assumed to have already crossed the pit. This decision was made based on the fact that most of solutions for stress intensity factors consider pits as 2D sharp cracks (see [8] [15] and [14]). After assembly, a dedicated cell is created for each pit. A fine localized mesh is needed to be able to capture 
the crack shape. For the dimensions of the pits considered in this study, 0.3 to $1 \mathrm{~mm}$ elements were generated around the pits (see Figure 18).

Damage initiation criteria can be defined for the existing cracks, which will delay the crack propagation until the initiation threshold is achieved. If no initial geometry is defined for the crack, a failure criterion needs to be defined. However, using this option is not straightforward since a specific corrosion initiation criterion is not currently available in the literature. The software struggles to define a well-shaped crack when cyclic load is applied with a non-fatigue based criteria such as maximum principal stress (MAXPS) and creates several parallel cracks when the cyclic load is applied. The partitioning and mesh generation was conducted with extra care and a mesh analysis tool was used to examine the mesh quality. For the crack surface contact properties, a hard contact with zero friction is considered in the finite element simulations.

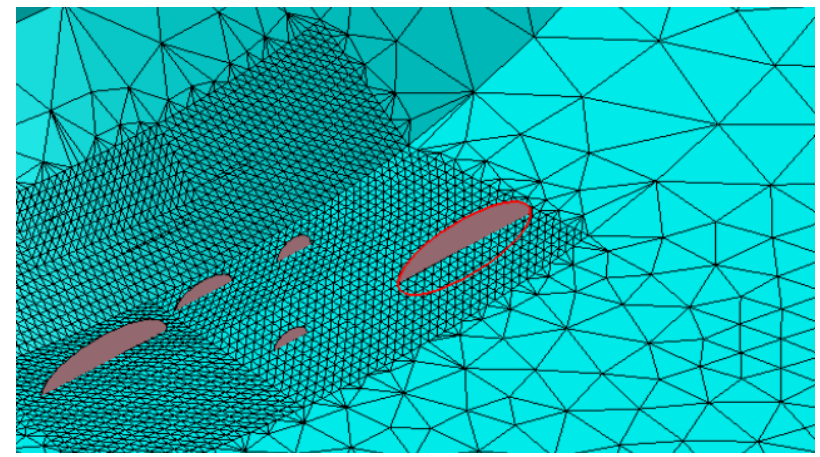

Figure 18: 2D pits in separate cells defined for XFEM cracks (The crack surface is the other half of the ellipse inside the material)

\section{Fatigue crack growth and defect assessment results}

\subsection{Quasi-static and cyclic stress analysis}

Based on the quasi-static simulation results for all load cases, the two locations with the highest maximum principal stresses were identified. The zones near weld fillets show the highest stress values at the WM and HAZ. Figure $19 \mathrm{a}, \mathrm{b}$ and $\mathrm{c}$ show an example of the stress output from the quasi-static simulation with high stress levels identified in location 1. 
This is a peer-reviewed, accepted author manuscript of the following article: Moghaddam, B. T., Hamedany, A. M., Taylor, J., Mehmanparast, A., Brennan, F., Davies, C. M., \& Nikbin, K. (2020). Structural integrity assessment of floating offshore wind turbine support structures. Ocean Engineering, 208, [107487]. https://doi.org/10.1016/j.oceaneng.2020.107487

a)

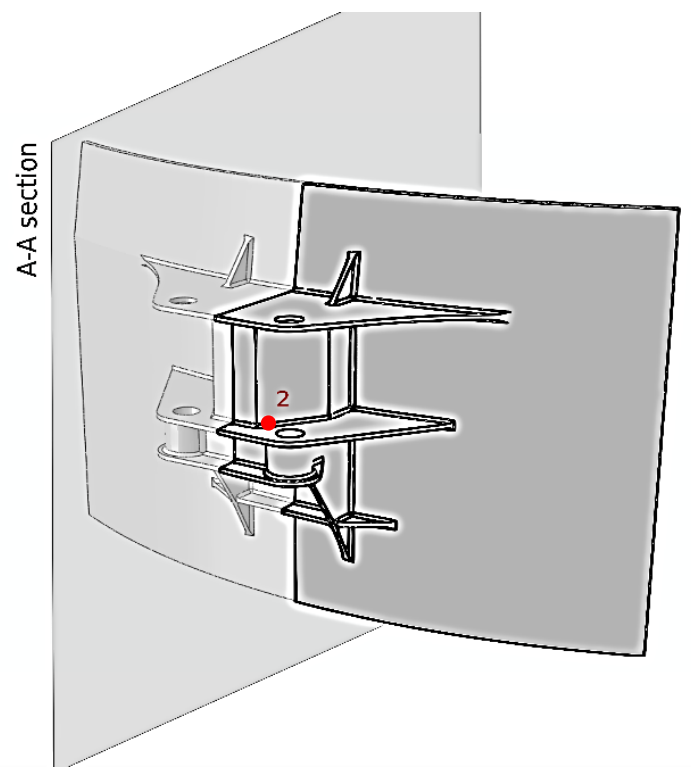

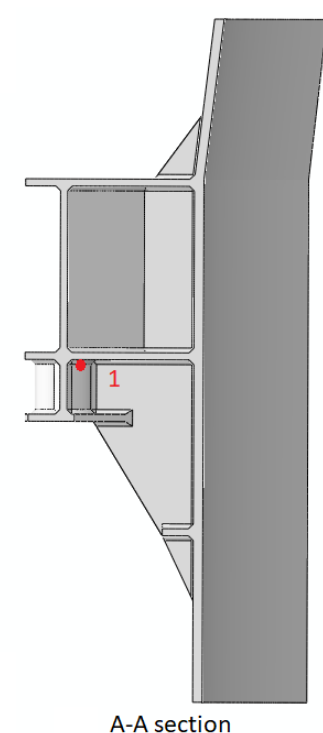

b)

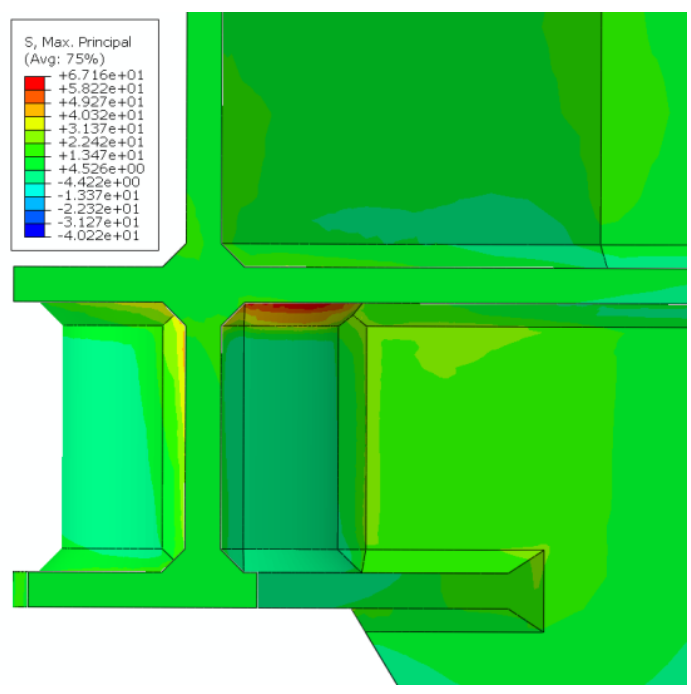

c)

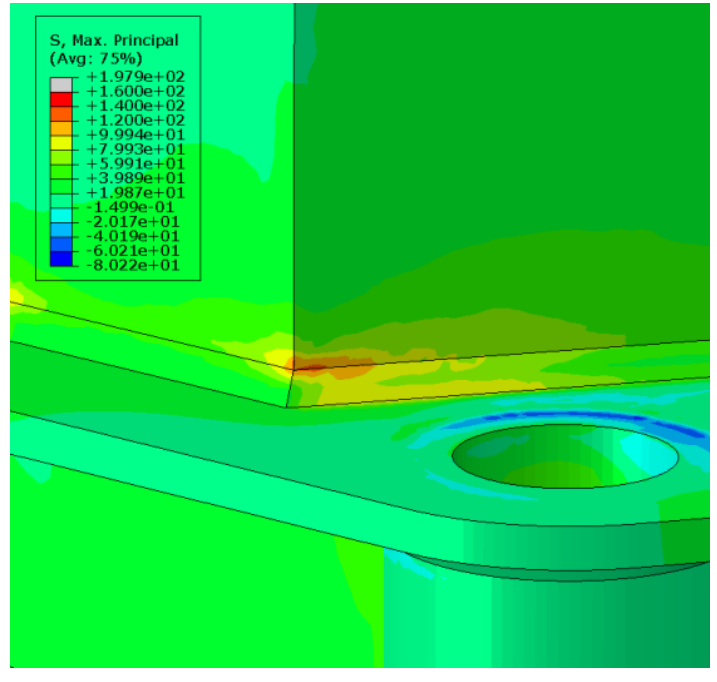

Figure 19: Locations and distribution of maximum principal stress with highest values (in MPa) 


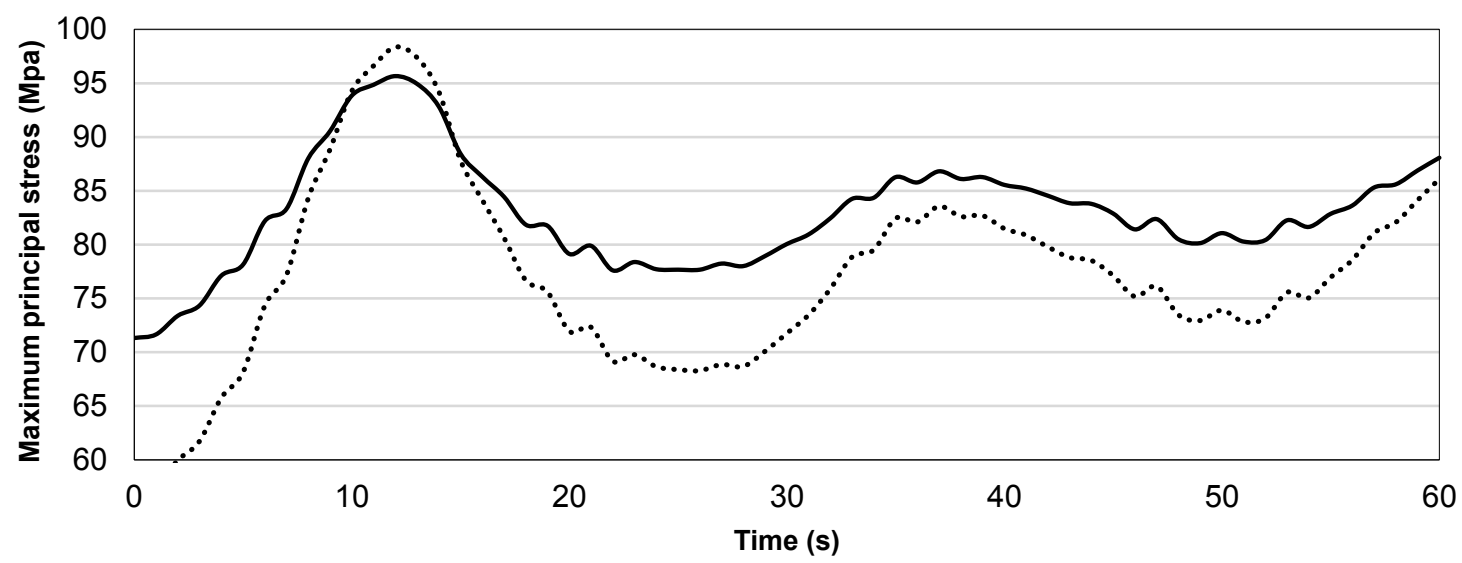

Figure 20: Example of maximum principal stress during 60 seconds of loads from $12 \mathrm{~m} / \mathrm{s}$ wind speed at locations 1, and 2 (dotted line).

Figure 20 shows an example of principal stresses in the structure critical points 1 and 2 for the simulation where the external loads (before Rainflow cycle counting) were applied. Figure 20 only shows the stresses for $12 \mathrm{~m} / \mathrm{s}$ wind speed for one wave input. Results from other wind/wave input show similar behaviour with the stresses following the same pattern but the amplitudes and mean values are not necessarily proportional.

Another simulation was carried out by applying external loads in the form of individual cycles from the Rainflow cycle counting results detailed in section 5.3. Rainflow-cycle count. The cyclic stress response for this analysis is presented in Table 6 . These stresses are inputted for defect assessments using Crackwise, the results of which are presented in the next section. From Table 6 it can be deduced that the $\mathrm{R}$ ratios are considerably large in the high stress intersection points between the mooring lines and the floating foundation, ranging from 0.6 to 0.9 .

Table 6: Cyclic stresses for different load cases obtained from numerical simulation

\begin{tabular}{cccc} 
Stress case & $\begin{array}{c}\text { Amplitude } \\
\text { (MPa) }\end{array}$ & $\begin{array}{c}\text { Mean } \\
\text { (MPa) }\end{array}$ & Cycle/year \\
\hline $\mathbf{1}$ & 8 & 61 & 19710 \\
$\mathbf{2}$ & 2 & 63 & 709998 \\
$\mathbf{3}$ & 3 & 63 & 19272 \\
$\mathbf{4}$ & 8 & 66 & 24790 \\
$\mathbf{5}$ & 6 & 92 & 24440 \\
$\mathbf{6}$ & 25 & 77 & 28995 \\
$\mathbf{7}$ & 12 & 70 & 27944 \\
$\mathbf{8}$ & 20 & 70 & 18658 \\
$\mathbf{9}$ & 30 & 70 & 11913 \\
$\mathbf{1 0}$ & 2 & 70 & 911565 \\
$\mathbf{1 1}$ & 4 & 71 & 22600 \\
$\mathbf{1 2}$ & 2 & 77 & 657876 \\
$\mathbf{1 3}$ & 8 & 77 & 38456 \\
$\mathbf{1 4}$ & 12 & 78 & 22075 \\
$\mathbf{1 5}$ & 21 & 76 & 29433 \\
$\mathbf{1 6}$ & 33 & 78 & 21286 \\
$\mathbf{1 7}$ & 39 & 76 & 11913 \\
$\mathbf{1 8}$ & 2 & 86 & 305986
\end{tabular}




\subsection{Single crack analysis}

\subsubsection{Finite element results}

Before considering multiple cracks in XFEM analysis, preliminary simulations were conducted in the presence of a single crack located in the high stress region (region 2) of the intersection point between the mooring line and the floating foundation (see Figure 19a). Simulations were performed for three $R$ ratios of $0.1,0.5$ and 0.8 with initial crack depths of $a_{0}=1.5$ and $3 \mathrm{~mm}$ and crack lengths of $2 c_{0}=4.17$ and $10.99 \mathrm{~mm}$. The single crack XFEM simulations were performed over the course of 2 years of operational life and the obtained results are presented in Table 7.

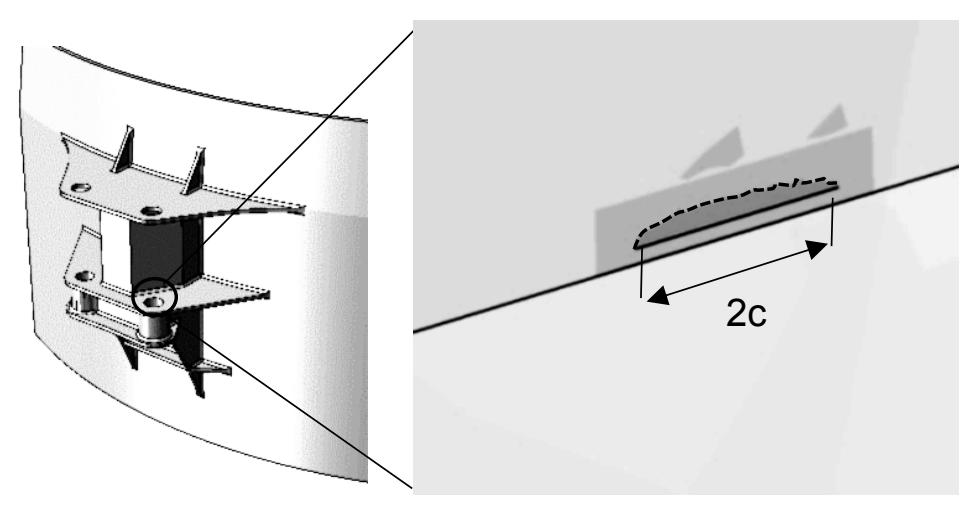

Figure 21: Single XFEM crack at location 2

Table 7: Crack growth $(\mathrm{mm})$ in two years

\begin{tabular}{ccccc}
$\mathbf{R}$ & $\mathbf{a} 0$ & $\mathbf{a}(\mathbf{2}$ years) & $\mathbf{2 \mathbf { c } _ { 0 }}$ & $\mathbf{2 c}$ (2 years) \\
\hline 0.1 & 1.5 & 1.58 & 4.17 & 4.47 \\
0.5 & 1.5 & 1.66 & 4.17 & 4.48 \\
0.8 & 1.5 & 1.51 & 4.17 & 4.77 \\
0.1 & 3.0 & 3.35 & 10.99 & 11.38 \\
0.5 & 3.0 & 3.40 & 10.99 & 11.39 \\
0.8 & 3.0 & 3.57 & 10.99 & 11.68
\end{tabular}

As seen in Table 7, the crack growth per year shows consistent results under varying $R$ ratios apart from the $1.5 \mathrm{~mm}$ initial crack at $\mathrm{R}=0.8$ which shows very little growth in depth with larger extension of crack length (2c). For $\mathrm{a}_{0}=1.5 \mathrm{~mm}$, the crack growth rates per year are well below the general corrosion rates, with the maximum of $0.08 \mathrm{~mm} /$ year (i.e. $0.16 \mathrm{~mm}$ in 2 years). For $a_{0}=3 \mathrm{~mm}$, on the other hand, the crack extends by $0.175 \mathrm{~mm} /$ year (i.e. $0.35 \mathrm{~mm}$ in 2 years) at $R=0.1$, and this value reaches 0.285 $\mathrm{mm} /$ year (i.e. $0.57 \mathrm{~mm}$ in 2 years) for $\mathrm{R}=0.8$.

\subsubsection{Crackwise results}

In order to verify the finite element prediction for a single crack, an analysis was carried out at the same location (location 2) using Crackwise to predict the crack growth also evaluate the critical crack size. Crackwise uses BS7910 guidelines in order to assess the integrity of pipelines, pressure equipment and structures that contain flaws. For fatigue crack growth, the software calculates the stress intensity factor for a crack with known dimensions and find the crack extension under the applied load using Paris law. Due to simplicity of Crackwise analysis compared to the finite element simulations, a larger number of cases were considered. The results for different $\mathrm{R}$ ratios of $0.1,0.5,0.7$ and 0.9 , plate thicknesses of 20 and $30 \mathrm{~mm}$, initial crack depths of 1.5, 3 and $5 \mathrm{~mm}$ and initial crack lengths of 6,12 and $20 \mathrm{~mm}$ are presented in Table 8 . Similar to finite element simulations, the Crackwise analyses were 
conducted for two years of operation using the T-Joint geometry as the closest shape to the location of the critical hot spots. A conservative stress concentration factor of 2.8 for the weld toe, as suggested by [53], was employed in these analyses.

Table 8: Crackwise results a single crack

\begin{tabular}{|c|c|c|c|c|c|c|}
\hline $\mathrm{R}$ ratio & $\begin{array}{c}\text { Thickness } \\
\text { (mm) }\end{array}$ & $\begin{array}{c}\mathbf{a}_{0} \\
(\mathbf{m m})\end{array}$ & $\begin{array}{c}\text { a (2 years) } \\
(\mathrm{mm})\end{array}$ & $\begin{array}{c}2 \mathbf{c}_{0} \\
(\mathbf{m m})\end{array}$ & $\begin{array}{c}2 \mathrm{c}(2 \\
\text { years }) \\
(\mathrm{mm})\end{array}$ & mm crack growth/year \\
\hline 0.1 & 30 & 1.5 & 1.52 & 6 & 6.19 & 0.01 \\
\hline 0.5 & 30 & 1.5 & 1.54 & 6 & 6.41 & 0.02 \\
\hline 0.7 & 30 & 1.5 & 1.59 & 6 & 6.82 & 0.05 \\
\hline 0.9 & 30 & 1.5 & 1.99 & 6 & 9.83 & 0.25 \\
\hline 0.1 & 20 & 1.5 & 1.57 & 6 & 6.49 & 0.04 \\
\hline 0.5 & 20 & 1.5 & 1.65 & 6 & 7.09 & 0.08 \\
\hline 0.7 & 20 & 1.5 & 1.83 & 6 & 8.25 & 0.17 \\
\hline 0.9 & 20 & 1.5 & 4.15 & 6 & 23.45 & 1.32 \\
\hline 0.1 & 30 & 3.0 & 3.05 & 12 & 11.63 & 0.02 \\
\hline 0.5 & 30 & 3.0 & 3.11 & 12 & 12.60 & 0.05 \\
\hline 0.7 & 30 & 3.0 & 3.22 & 12 & 14.55 & 0.11 \\
\hline 0.9 & 30 & 3.0 & 4.25 & 12 & 23.91 & 0.62 \\
\hline 0.1 & 20 & 3.0 & 3.16 & 12 & 13.59 & 0.08 \\
\hline 0.5 & 20 & 3.0 & 3.38 & 12 & 15.52 & 0.19 \\
\hline 0.7 & 20 & 3.0 & 3.84 & 12 & 19.35 & 0.42 \\
\hline 0.9 & 20 & 3.0 & 18.36 & 12 & 139.82 & 8.93 \\
\hline 0.1 & 30 & 5.0 & 5.09 & 20 & 21.46 & 0.04 \\
\hline 0.5 & 30 & 5.0 & 5.21 & 20 & 23.13 & 0.10 \\
\hline 0.7 & 30 & 5.0 & 5.43 & 20 & 26.12 & 0.22 \\
\hline 0.9 & 30 & 5.0 & 7.75 & 20 & 50.03 & 1.37 \\
\hline 0.1 & 20 & 5.0 & 5.33 & 20 & 24.13 & 0.17 \\
\hline 0.5 & 20 & 5.0 & 5.81 & 20 & 29.29 & 0.41 \\
\hline 0.7 & 20 & 5.0 & 7.06 & 20 & 40.68 & 1.03 \\
\hline 0.9 & 20 & 5.0 & 18.74 & 20 & 143.31 & 14.62 \\
\hline
\end{tabular}

The results show that for $30 \mathrm{~mm}$ thick plates, the crack growth is not significant for the wide range of $\mathrm{R}$ ratios considered in the analyses - i.e. it is below the general corrosion rate. However for $R=0.9$ the crack growth exceeds the general corrosion rate of $0.2 \mathrm{~mm} / \mathrm{year}$. Similar observations can be made for the thinner plate of $20 \mathrm{~mm}$, however for this plate thickness higher crack growth than the general corrosion rate can be seen at $\mathrm{R}$ ratio of 0.7 as well as 0.9 when the initial crack depths are equal to or greater than $3 \mathrm{~mm}$. The analysis shows that for the plate thickness of $20 \mathrm{~mm}$ at $R=0.9$, the structure will fail in 1.7 and 0.9 years assuming initial crack depths of 3 and $5 \mathrm{~mm}$ respectively. It is worth noting that $5 \mathrm{~mm}$ initial crack depth is extremely rare based on the probability distribution used in this study. Since general corrosion is continually happening while the crack is growing, the current analysis is still conservative as the crack size is measured from the initial surface. Comparing the Crackwise analysis results with those of obtained from XFEM simulations in section 6.2.1, it is evident that the XFEM results are generally in agreement with the Crackwise results for the case of a single crack. 
Further sensitivity analysis has been performed to investigate the amount of crack growth from individual load cycles in order to find the highest contributing stress amplitude on the fatigue crack growth. Although the individual stress amplitude analysis is not directly comparable with combination of stress amplitudes, this analysis is still useful to identify the level of contribution for different amplitudes to the amount of total crack growth. Figure 22 shows the contribution of each load cycle to crack growth if applied individually. As seen in this figure the percentage of crack growth increases exponentially as the cyclic stress amplitude increases beyond $30 \mathrm{MPa}$. As observed clearly in this figure the higher amplitude stresses cause greater crack growth while the lower stress amplitudes, which are often repeated for higher number of cycles during normal operational conditions, have less contribution to the crack growth.

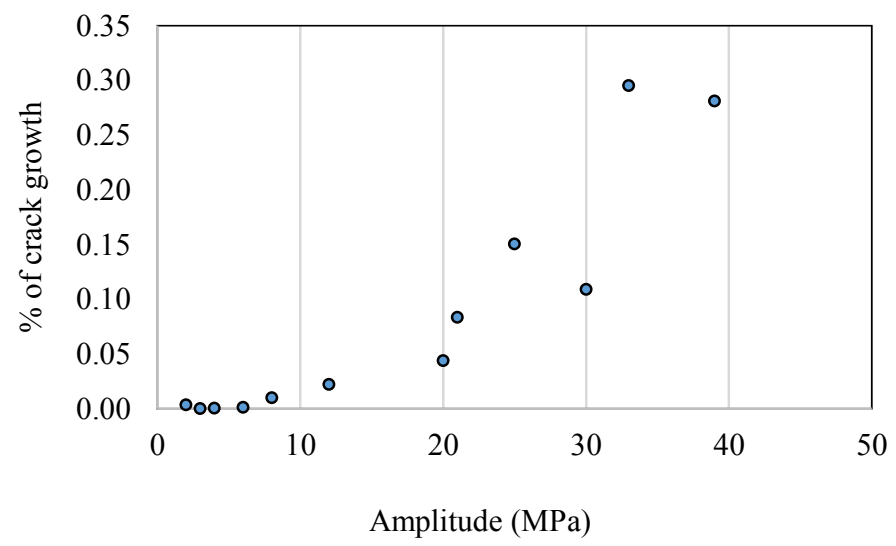

Figure 22: Contribution of each load cycles to crack growth if applied individually

The crack growth results obtained from Crackwise analysis in Table 8 are only for normal operational loading conditions. A critical load analysis is also carried out for a plate thickness of $30 \mathrm{~mm}$ to find the critical flaw depth if the structure is subjected to large loads due to the storm events. The results are presented in Table 9. Also included in this table are the critical crack sizes for $30 \mathrm{~mm}$ a thickness plate at different membrane stress levels. As seen in this table, the analysis indicates failure when the membrane stress reaches $500 \mathrm{MPa}$ which is much greater than the operational loading condition. This is important as cracks which are not large enough to cause failure by fatigue can be large enough to cause failure under large loads during the storm or collision events.

Table 9: Extreme loading condition and critical crack sizes

\begin{tabular}{ccc}
$\begin{array}{c}\text { Primary membrane stress } \\
\text { (MPa) }\end{array}$ & $\begin{array}{c}\text { Critical crack depth } \\
(\mathbf{m m})\end{array}$ & Result \\
\hline 0 & 30 & Acceptable \\
50 & 30 & Acceptable \\
100 & 30 & Acceptable \\
150 & 26.0 & Acceptable \\
200 & 21.2 & Acceptable \\
250 & 17.7 & Acceptable \\
300 & 14.9 & Acceptable \\
350 & 12.5 & Acceptable
\end{tabular}




$\begin{array}{llc}400 & 7.7 & \text { Acceptable } \\ 450 & 2.2 & \text { Acceptable } \\ 500 & 0.1 & \text { Unacceptable }\end{array}$

\subsection{Crack growth simulations using XFEM in the presence of multiple pits}

As shown previously, the XFEM framework is verified through comparison with Crackwise analyses for the case of a single crack. Due to the limitation of the Crackwise procedure, which cannot consider more than one crack in a given geometry, XFEM simulations are performed in the presence of multiple cracks and the predicted results are presented and discussed in this section. In XFEM analysis, multiple cracks were defined to assess the fatigue crack behaviour when a distribution of cracks/pits exist at the WM and HAZ. For this analysis two hot spot regions with the highest local stress levels have been considered and analysed separately. All of these analyses are for 2 years of operation in the presence of multiple cracks.

\subsubsection{Region 1}

The first considered region is location 1 , which has the highest stress levels in the structure (from the unflawed model-see 6.1. Quasi-static and cyclic stress analysis). The location and orientation of the randomly assigned corrosion pits in this high stress zone is shown in Figure 23. The initial crack depths are $3.24 \mathrm{~mm}, 3.66 \mathrm{~mm}, 2.94 \mathrm{~mm}, 3.16 \mathrm{~mm}$ and $3.65 \mathrm{~mm}$, for crack 1 to 5 respectively. The crack widths, in the same order, are: $8.77 \mathrm{~mm}, 7.96 \mathrm{~mm}, 6.06 \mathrm{~mm}, 4.3 \mathrm{~mm}$ and $9.7 \mathrm{~mm}$. The crack growth results obtained for three different $R$ ratios of $0.1,0.5$ and 0.7 are shown in Figure 24 and Figure 25.

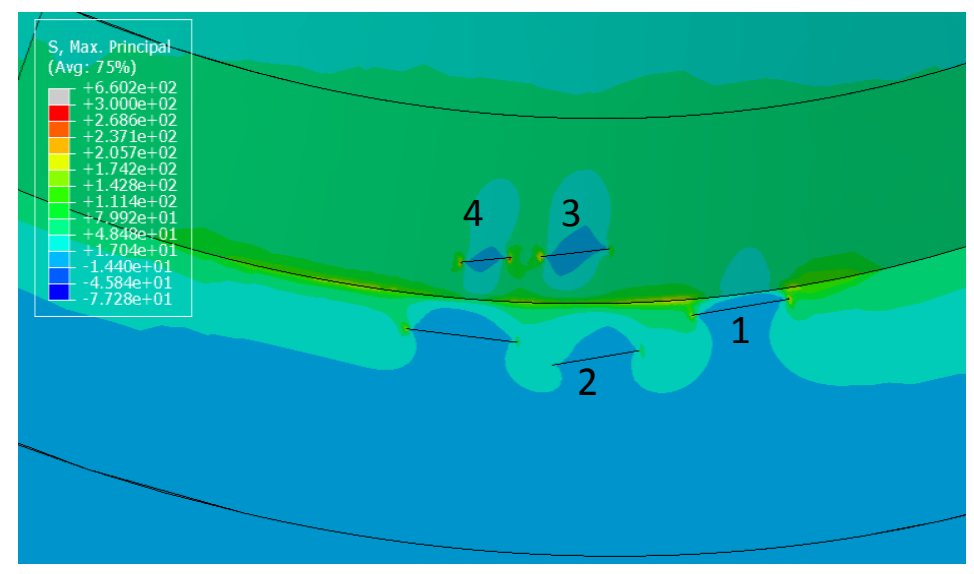

Figure 23 Location of the measured cracks. 


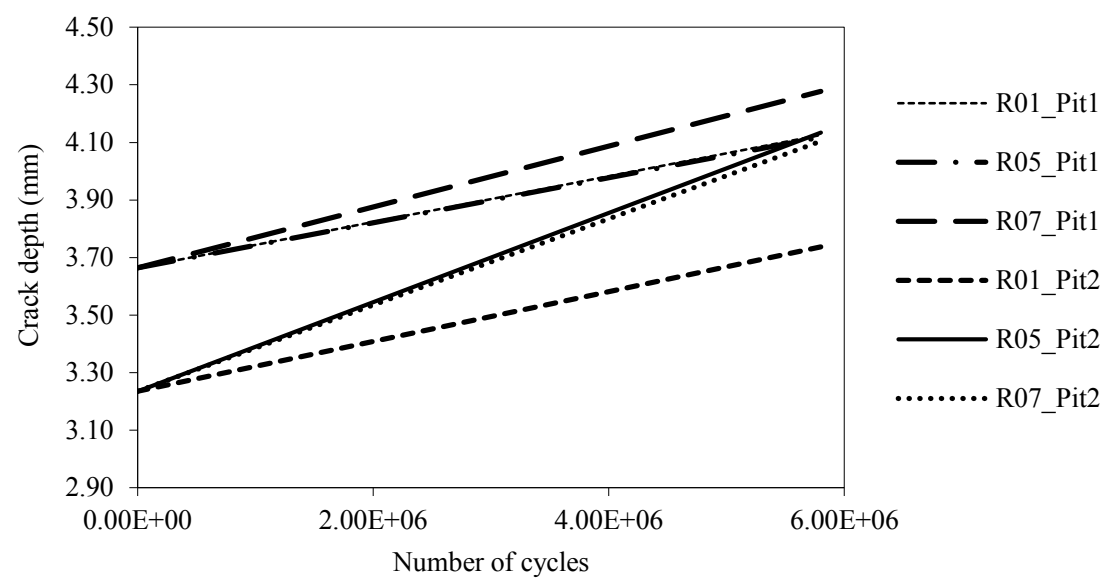

Figure 24 Crack growth rate in the HAZ for different $R$ ratios

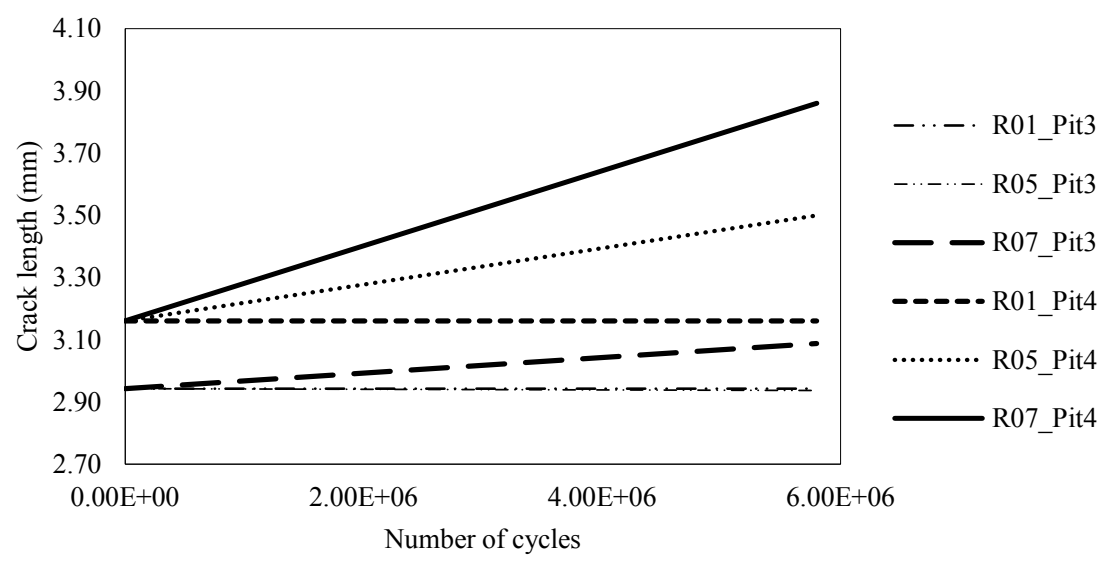

Figure 25 Crack growth rate in the WM for different $R$ ratios

As seen in figures Figure 24 and Figure 25, the cracks show growth above the general corrosion rate of $0.2 \mathrm{~mm} /$ year. However in some cases, depending on the location of the crack, the crack can grow at a lower or higher rate over two years of operation. As seen in these figures, crack growth of up to 0.45 $\mathrm{mm} /$ year is observed for $\mathrm{R}$ ratio greater than or equal to 0.5 from large initial cracks with $3.2 \mathrm{~mm}$ depth (Pit 2 in Figure 23). This value is greater than the general corrosion rate of $0.2 \mathrm{~mm} /$ year, which indicates that the crack from this pit will continue propagating without being ground by the general corrosion effect. In the same model, Pit 1, which is a deeper crack compared to Pit 2, shows a lower crack growth rate at the $\mathrm{R}$ ratio of 0.7 compared to the crack growth rate observed in Pit 2 . This can be due to the fact that the neighbouring pits have grown faster at the higher $R$ ratio and the stress values have dropped in the vicinity of Pit 1 . Moreover, the crack orientation with respect to the maximum principal stress direction may have caused lower crack growth rate in Pit 1 compared to Pit 2 at $R$ ratio of 0.7.

\subsubsection{Region 2}

The second considered region (location 2) has an average of $70 \mathrm{MPa}$ maximum principal stress. The location and orientation of the randomly assigned corrosion pits in this high stress zone is shown in Figure 26. The initial crack depths for cracks 1 to 4 are: $3.81 \mathrm{~mm}, 2.2 \mathrm{~mm}, 2.6 \mathrm{~mm}$ and $0.98 \mathrm{~mm}$. The crack widths are $11.8 \mathrm{~mm}, 4.04 \mathrm{~mm}, 7.9 \mathrm{~mm}$ and $5.36 \mathrm{~mm}$ in similar order. The crack growth results obtained for three different $R$ ratios of $0.1,0.5$ and 0.7 are shown in Figure 27 and Figure 28. The growth of four dominant cracks is reported. Comparing the crack propagation rates in these figures with 
This is a peer-reviewed, accepted author manuscript of the following article: Moghaddam, B. T., Hamedany, A. M., Taylor, J., Mehmanparast, A., Brennan, F., Davies, C. M., \& Nikbin, K. (2020). Structural integrity assessment of floating offshore wind turbine support structures. Ocean Engineering, 208, [107487]. https://doi.org/10.1016/j.oceaneng.2020.107487

those presented in Figure 24 and Figure 25, it can be seen that higher crack growth rates are observed in this region which is close to the edge compared to the first region considered in section 6.3.1. Region 1 , even though region 1 had a higher stress level. The crack extension in the bulk of the material is demonstrated in Figure 29 to better illustrate the crack propagation in the structure along the throughthickness direction.

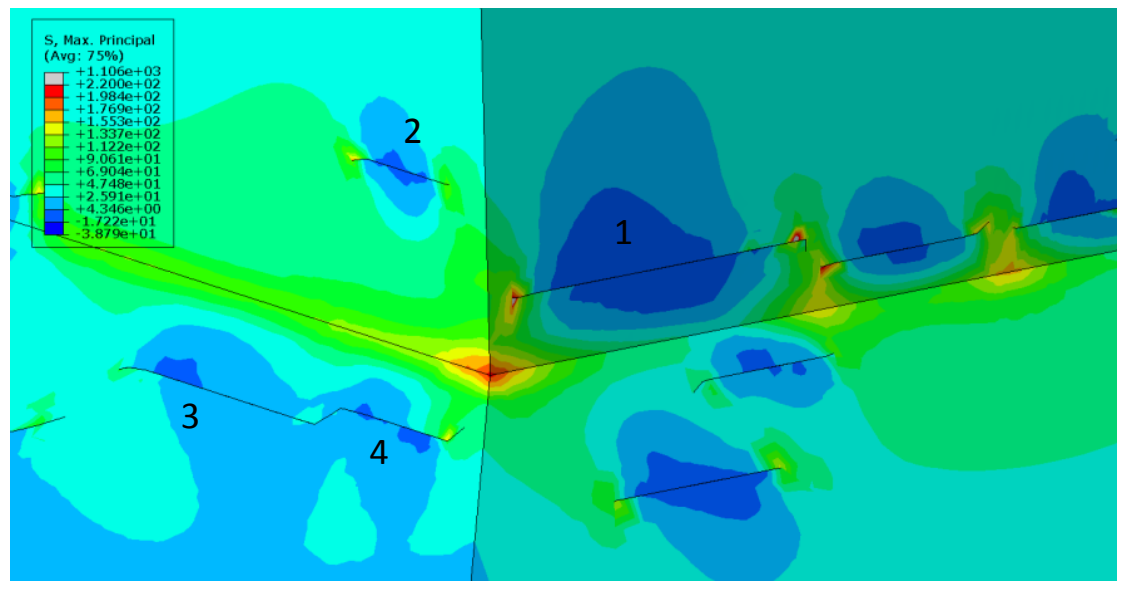

Figure 26: Randomly generated cracks in location 2. ... final:11.88, 5.56, 16.04 (the two cracks collided)

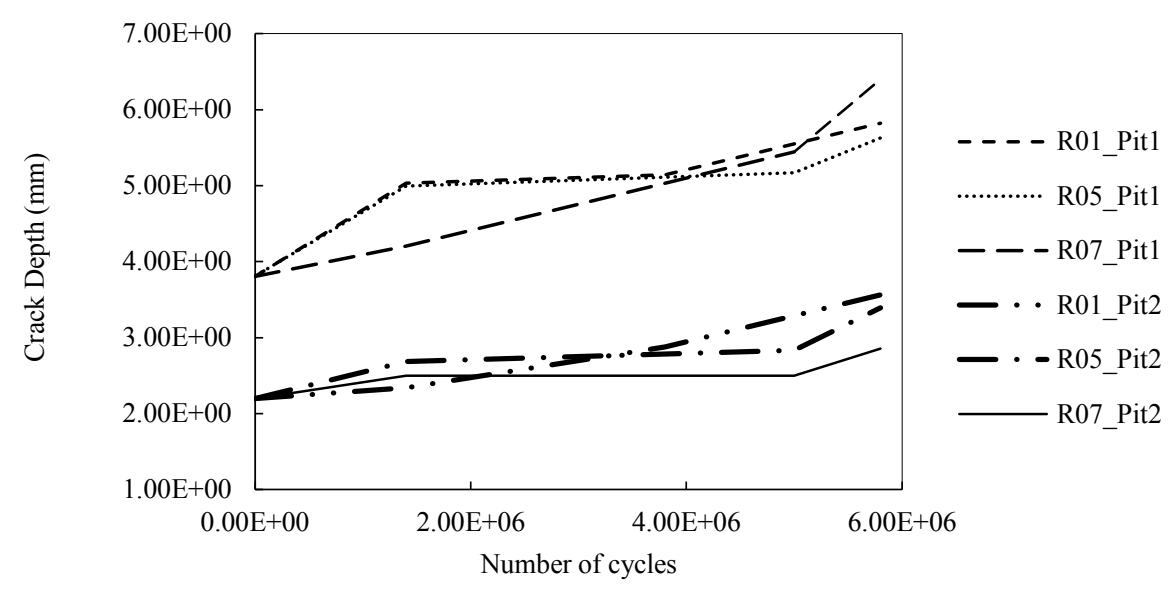

Figure 27 Crack growth in the HAZ over two years from two pits at different $R$ ratios (pit 1 \& 2)

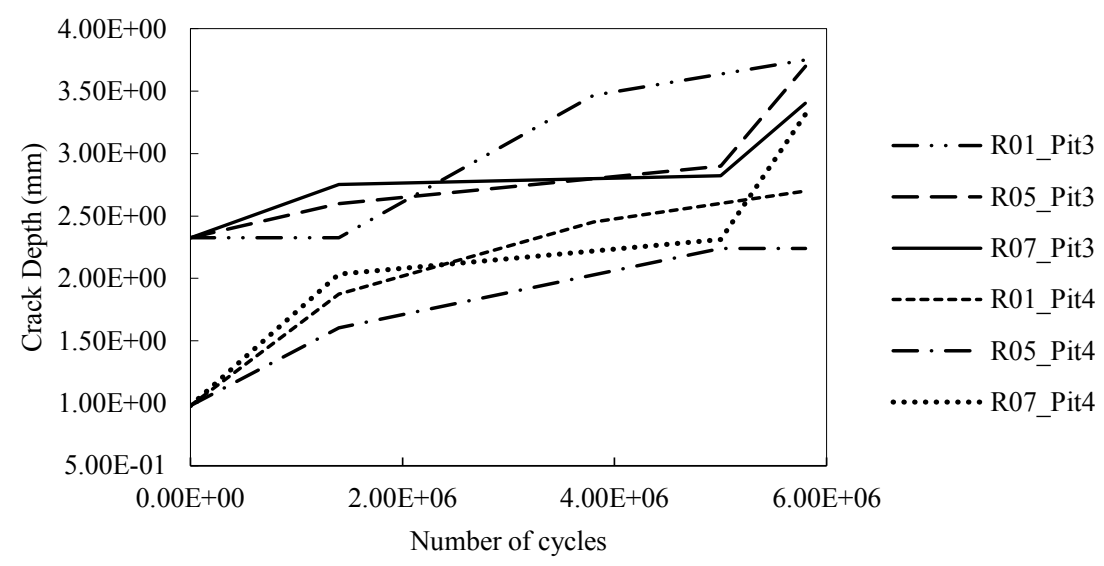

Figure 28 Crack growth in the WM over two years from two pits at different $R$ ratios (pit 3 \& 4) 


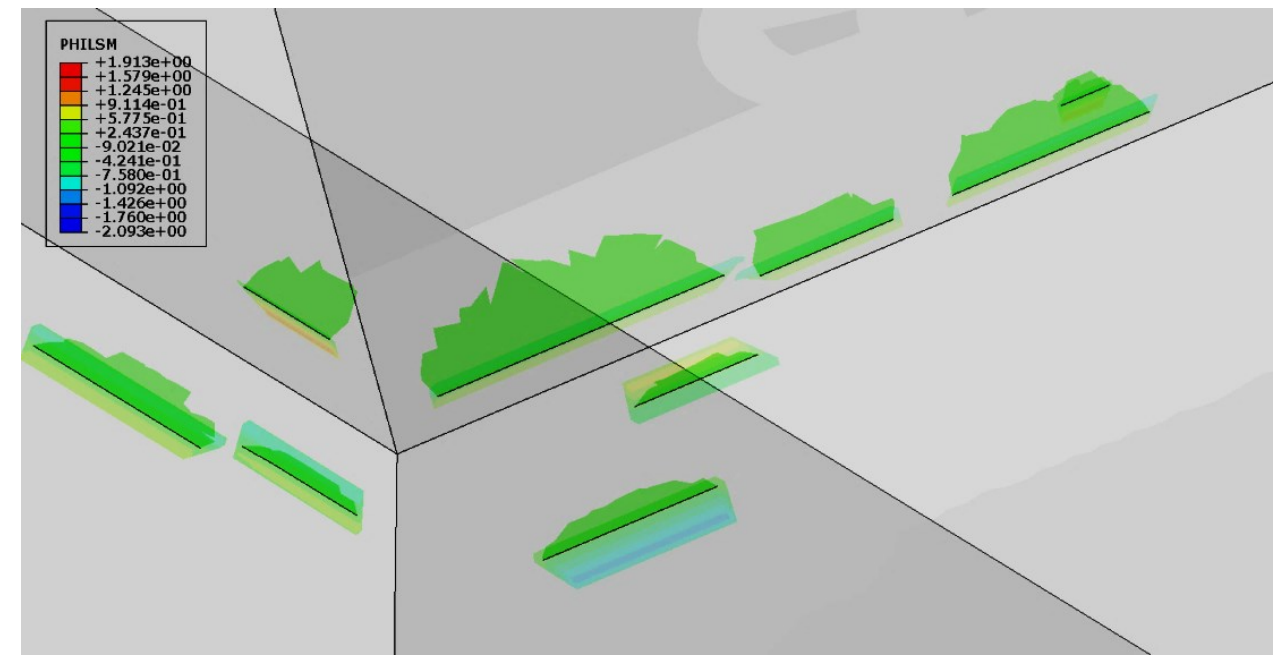

Figure 29: Crack growth at the edge in the HAZ and WM (lower section)

As seen in Figure 27, Pit 1 (with initial crack depth of $\mathrm{a}_{0}=3.8 \mathrm{~mm}$ ) shows the largest crack growth with almost $1-1.3 \mathrm{~mm} /$ year for all $\mathrm{R}$ ratios. This pit is located just at the edge of the weld region which experiences higher through thickness stress distribution (see Figure 26). This shows the importance of the pit location and orientation with respect to the weld geometry which can significantly influence the crack propagation and subsequently fracture behaviour of the structure. Figure 27 and Figure 28 show the crack size for two dominant pits in each zone over 5.8 million cycles (i.e. 2 years of operational cycles). For Pit 1 and Pit 4 the crack growth rate increases with an increase in R ratio, however a reverse trend has been observed in Pit 2 and Pit 3 . This might be due to the faster crack growth in neighbouring pits and stress redistribution around Pit 2 and Pit 3 which has resulted in lower crack growth rates at higher $\mathrm{R}$ ratios in these two pits.

\subsubsection{Crack coalescence}

In XFEM simulations with multiple cracks, there are several cases in which crack coalescence has been noted. This usually happens when the cracks are close to each other and aligned along the same or similar planes. An example of crack coalescence in XFEM simulations is shown in Figure 30 . It has been noted that the collision of the cracks does not cause much increase in the size of the crack. This can be due to the fact that the crack intensity is mostly influenced by its depth and collision does not cause increase in crack depth, but instead simplifies the features of the cracked geometry by merging multiple crack when they are very close to each other and start to propagate into each other's crack planes. 

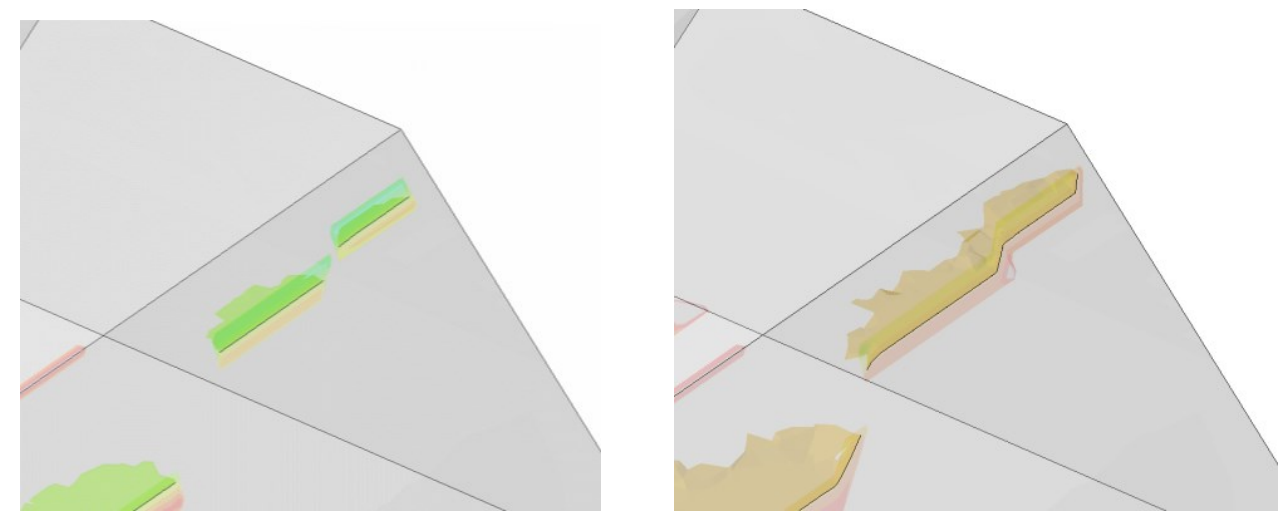

Figure 30: Crack coalescence

\subsection{Crackwise simulations for 20 years of operational life cycles}

As shown previously in 6.2. Single crack analysis, the developed XFEM framework has been found to result in similar predictions with Crackwise analyses for the case of a single crack. Due to the simplicity of the Crackwise procedure, further Crackwise simulations have been performed to examine the crack propagation (i.e. single crack) behaviour in the intersection point between the mooring point and the floating foundation for 20 years of operational life. Simulations have been performed on plates with the thickness of 20 and $30 \mathrm{~mm}$ for $\mathrm{R}$ ratios of $0.1,0.5,0.7$ and 0.9 and crack depths of $1.5,3$ and $5 \mathrm{~mm}$, and the results are summarised in Table 10, and shown in Figure 31 and Figure 32 for plate thickness of 30 and $20 \mathrm{~mm}$, respectively. The results show in both plate thicknesses, for crack depths of $1.5 \mathrm{~mm}$ the propagation rates of greater than the general corrosion rate occurs only at the $\mathrm{R}$ ratio of 0.9 and for all other $\mathrm{R}$ ratios the crack growth is less than the general corrosion for 20 years of operation.

Also seen in Table 10 and Figure 31 and Figure 32 is that for the initial crack depth of $3 \mathrm{~mm}$, higher crack growth rates than the general corrosion rate occur at $R$ ratio of 0.9 for plate thickness of $30 \mathrm{~mm}$ and $R$ ratios of 0.7 and 0.9 for plate thickness of $20 \mathrm{~mm}$. Moreover, for the initial crack depth of $5 \mathrm{~mm}$, higher crack growth rates than the general corrosion rate are observed for $\mathrm{R}$ ratios of 0.7 and 0.9 in the plate thickness of $30 \mathrm{~mm}$, and $R$ ratios of $0.5,0.7$ and 0.9 in the plate thickness of $20 \mathrm{~mm}$. Also seen in these results are the predicted number of years to failure for those cases that the corrosion fatigue cracks continue to propagate at a rate higher than the general corrosion rate. As seen in these results, for the extreme cases at the $R$ ratio of 0.9 with initial crack depth of $5 \mathrm{~mm}$, the expected life can be as low as 4 and 1 year for the plate thickness of 30 and $20 \mathrm{~mm}$, respectively. Finally seen in Figure 31 and Figure 32 is that at the highest considered $R$ ratio of 0.9 , the crack growth experiences a sharp rise after a certain crack size which is $13 \mathrm{~mm}$ for $30 \mathrm{~mm}$ plate and close to $8-10 \mathrm{~mm}$ for the $20 \mathrm{~mm}$ plate, beyond which the time-to-failure is only around 1-2 years. For smaller $\mathrm{R}$ ratios the crack growth behaviour shows a less dramatic rise, hence longer lives of 3-5 years before failure.

Table 10: Crackwise results for 20 years of operational life cycles

\begin{tabular}{|c|c|c|c|c|c|c|c|}
\hline $\begin{array}{c}\mathrm{R} \\
\text { ratio }\end{array}$ & $\begin{array}{c}\text { Thickness } \\
\text { (mm) }\end{array}$ & $\begin{array}{c}\mathbf{a}_{0} \\
(\mathbf{m m})\end{array}$ & $\begin{array}{c}\text { a (20 years) } \\
(\mathrm{mm})\end{array}$ & $\begin{array}{c}2 \mathbf{c}_{0} \\
(\mathbf{m m})\end{array}$ & $\begin{array}{c}2 \mathrm{c}(20 \text { years }) \\
(\mathrm{mm})\end{array}$ & $\begin{array}{c}\text { Above/below } \\
\text { general } \\
\text { corrosion }(G C) \\
\text { rate } \\
\end{array}$ & $\begin{array}{l}\text { Number } \\
\text { of years } \\
\text { to failure }\end{array}$ \\
\hline 0.1 & 30 & 1.5 & 1.76 & 6 & 8.09 & bellow GC & - \\
\hline 0.5 & 30 & 1.5 & 2.17 & 6 & 11.03 & bellow GC & - \\
\hline 0.7 & 30 & 1.5 & 3.29 & 6 & 18.95 & bellow GC & - \\
\hline
\end{tabular}


This is a peer-reviewed, accepted author manuscript of the following article: Moghaddam, B. T., Hamedany, A. M., Taylor, J., Mehmanparast, A., Brennan, F., Davies, C. M., \& Nikbin, K. (2020). Structural integrity assessment of floating offshore wind turbine support structures. Ocean Engineering, 208, [107487]. https://doi.org/10.1016/j.oceaneng.2020.107487

$\begin{array}{cccccccc}0.9 & 30 & 1.5 & 27.88 & 6 & 248.94 & \text { above GC } & 10.6 \\ 0.1 & 20 & 1.5 & 2.56 & 6 & 12.89 & \text { bellow GC } & - \\ 0.5 & 20 & 1.5 & 6.00 & 6 & 36.85 & \text { bellow GC } & - \\ 0.7 & 20 & 1.5 & 18.11 & 6 & 137.31 & \text { below GC } & - \\ 0.9 & 20 & 1.5 & 16.36 & 6 & 120.05 & \text { above GC } & 3.2 \\ 0.1 & 30 & 3 & 3.63 & 12 & 18.45 & \text { bellow GC } & - \\ 0.5 & 30 & 3 & 4.72 & 12 & 27.82 & \text { bellow GC } & - \\ 0.7 & 30 & 3 & 8.56 & 12 & 60.28 & \text { bellow GC } & - \\ 0.9 & 30 & 3 & 26.99 & 12 & 238.20 & \text { above GC } & 6.4 \\ 0.1 & 20 & 3 & 6.22 & 12 & 37.74 & \text { bellow GC } & - \\ 0.5 & 20 & 3 & 18.76 & 12 & 143.90 & \text { below GC } & - \\ 0.7 & 20 & 3 & 18.47 & 12 & 140.89 & \text { above GC } & 7.2 \\ 0.9 & 20 & 3 & 17.2075 & 12 & 128.01 & \text { above GC } & 1.8 \\ 0.1 & 30 & 5 & 6.28403 & 20 & 35.59 & \text { bellow GC } & - \\ 0.5 & 30 & 5 & 9.00928 & 20 & 61.89 & \text { bellow GC } & - \\ 0.7 & 30 & 5 & 29.3067 & 20 & 266.56 & \text { above GC } & 16.4 \\ 0.9 & 30 & 5 & 29.1068 & 20 & 263.66 & \text { above GC } & 4 \\ 0.1 & 20 & 5 & 18.7814 & 20 & 143.73 & \text { below GC } & - \\ 0.5 & 20 & 5 & 18.8016 & 20 & 143.92 & \text { above GC } & 7.4 \\ 0.7 & 20 & 5 & 18.8704 & 20 & 144.61 & \text { above GC } & 4 \\ 0.9 & 20 & 5 & 17.41 & 20 & 129.50 & \text { above GC } & 1\end{array}$

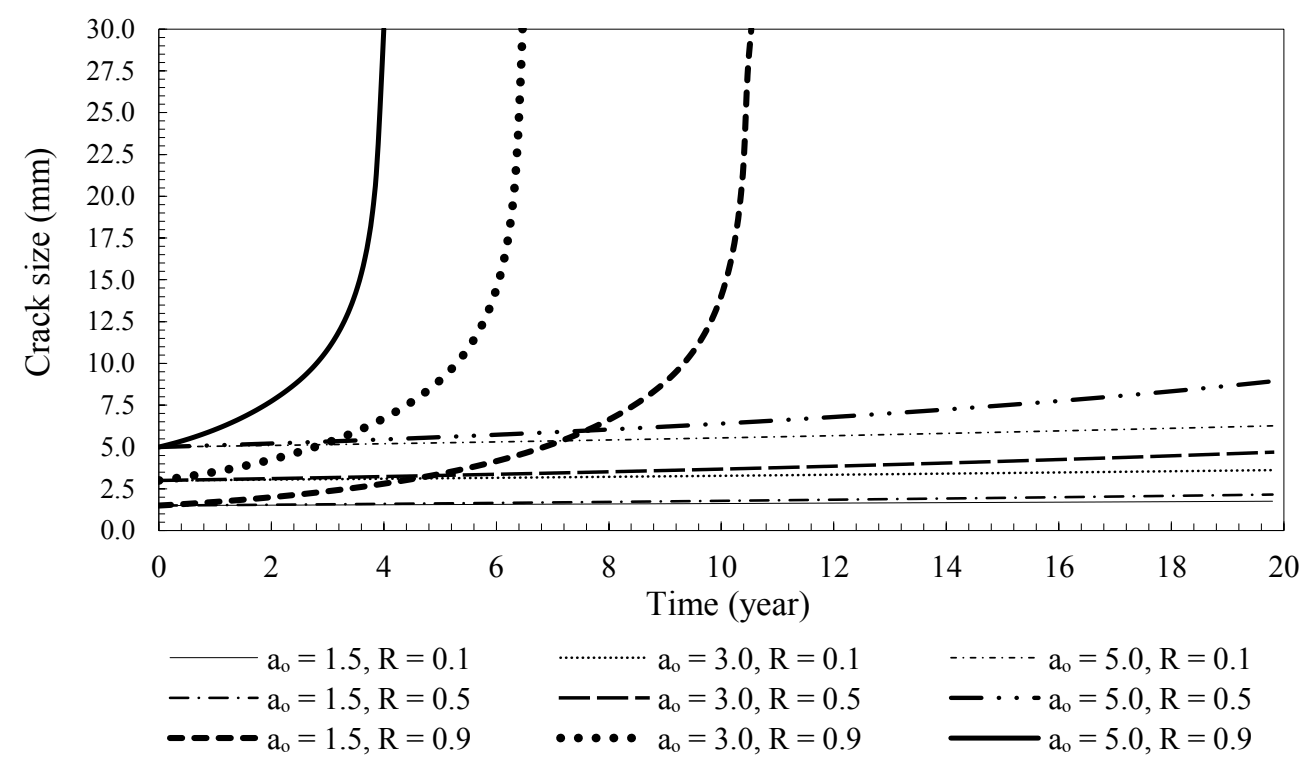

Figure 31: Crack size during 20 years for $30 \mathrm{~mm}$ plate thickness 


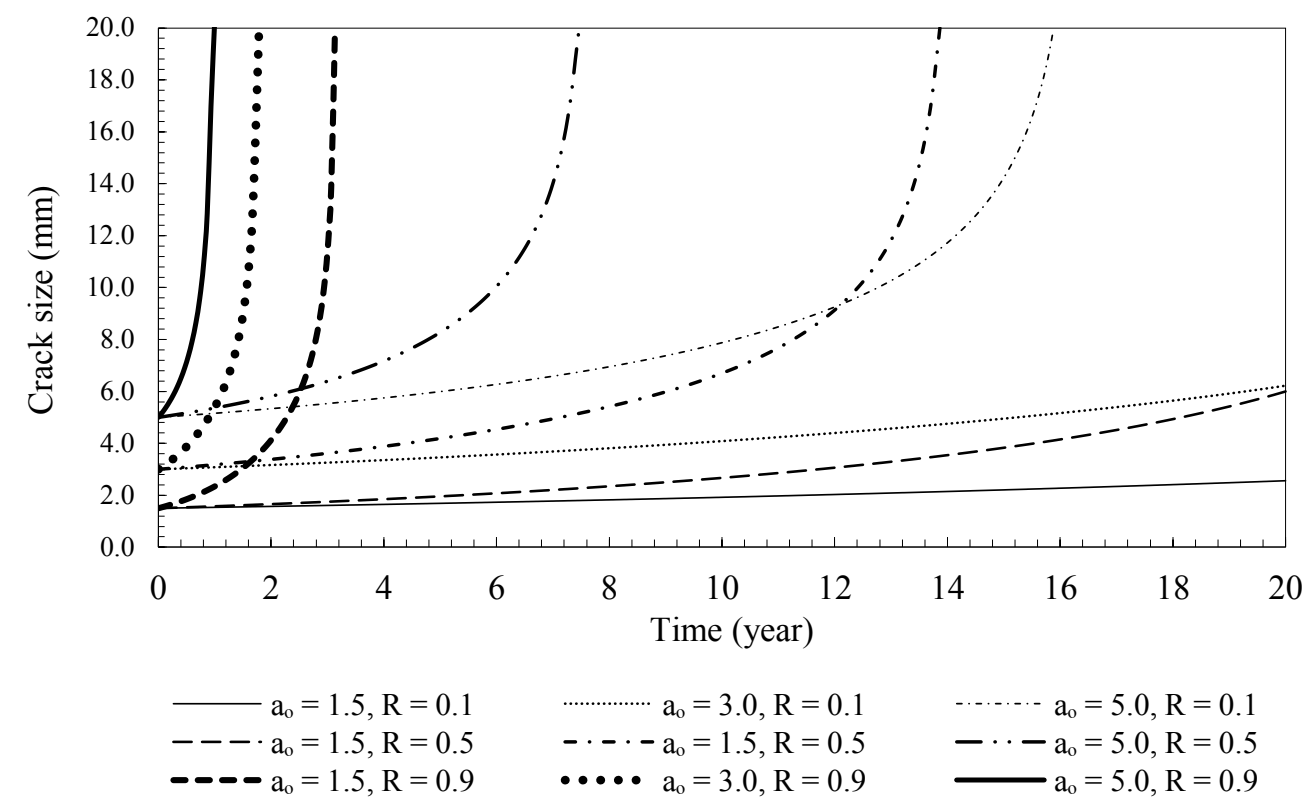

Figure 32: Crack size during 20 years for $20 \mathrm{~mm}$ plate thickness

\section{Discussion}

The results from Crackwise and XFEM analyses show that high amplitude loads with small frequencies are responsible for the crack growth to a large extent in floating offshore wind turbine structures. This indicates that the likelihood of fatigue crack propagation and eventual fracture can be reduced significantly if these cyclic loads are mechanically damped or removed. It should be noted that this analysis does not consider the change in crack growth rate at different crack lengths for combined load cases and only one load case is applied in the simulations at a given time (i.e. in each step). However, further investigation will be conducted in future work to assess the severity of damage from each cyclic load in the overall fatigue crack growth behaviour in offshore floating structures.

The fatigue crack propagation results from XFEM and Crackwise in the presence of a single corrosion pit show that an increase in the $R$ ratio increases the crack growth rates. In the case of multiple cracks in XFEM simulations, the trend is the same for almost all cases however, exceptions exist which might be associated with the interaction between the pits, and large and rapid extension in one crack which may reduce the growth rate in the adjacent pitting crack due to the local stress redistributions. It must be noted that the welding residual stresses have not been directly included in any of the simulations performed in this study. However knowing that tensile residual stresses increase the mean stress (hence result in higher $\mathrm{R}$ ratios) and compressive residuals stresses decrease the mean stress (hence result in lower $R$ ratios), the sensitivity analysis over a wide range of $R$ ratio between 0.1 and 0.9 reveals the severe damaging influence of tensile residual stresses in corrosion pitting fatigue crack growth behaviour of the material in floating offshore wind turbine foundations.

In this study, several cases of crack coalescence were observed in the XFEM simulations. The most important factor in collision of cracks is the proximity of the two pits/cracks and alignment of their crack planes. In practice, the collided cracks, after coalescence, can be considered as a single crack with the total crack length (i.e. 2c) of equal to the summation of individual crack lengths before coalescence. On the other hand the merged crack depth has the value of equal to the larger crack depth before coalesces, without the individual crack depths being added to each other. It is worth noting that the 
This is a peer-reviewed, accepted author manuscript of the following article: Moghaddam, B. T., Hamedany, A. M., Taylor, J., Mehmanparast, A., Brennan, F., Davies, C. M., \& Nikbin, K. (2020). Structural integrity assessment of floating offshore wind turbine support structures. Ocean Engineering, 208, [107487]. https://doi.org/10.1016/j.oceaneng.2020.107487

fatigue analysis is heavily dependent on the crack depth (i.e. a) in the criticality assessment of the crack size rather than the crack length (2c), therefore crack coalescence does not seem to have a significant effect on the assessment of the critical crack size.

The fracture mechanics analysis on the mooring point suggests that the geometrical details can play a critical role in the fatigue life assessment of these floating structures. Sharp edges, for instance the weld toes, with higher stress concentration factors can cause larger crack extensions for the pits/cracks which are close enough to this edge. Therefore, less sharp edges and corners in the design can improve the fatigue and fracture resistance of these floating structures. This indicates that a sensitivity analysis needs to be performed in future work to evaluate the fabrication quality effects on the fatigue life assessment of floating offshore wind turbine foundations by accounting for a range of stress concentration factors in numerical simulations.

The Paris law constants used in this study have been taken from the SLIC project [44] in which the corrosion-fatigue tests were conducted at the frequency of $0.3 \mathrm{~Hz}$, which is suitable for bottom-fixed offshore wind monopile foundations. However, the analysis performed in the present study has shown that the operational frequency in floating offshore wind turbine foundations is about $0.2 \mathrm{~Hz}$. Therefore, there is a need to examine the frequency effects on the corrosion-fatigue crack growth behaviour of the material in future work. For the marine environment in particular, various frequencies can alter the fatigue behaviour as well as pitting and crack initiation itself. These topics are currently research gaps in the literature and further investigation is required for more accurate characterization of corrosion pitting crack propagation in offshore floating structures.

The present study is performed based on the normal loading conditions experienced by floating offshore wind turbines. Another important consideration for better life assessment of these offshore fleets is to account for the overload and extreme loading conditions during storm events in the numerical analyses. Therefore, it is needed to perform further studies as future work to examine the influence of overloads on corrosion pitting, crack initiation and crack propagation behaviour of the material in floating structures.

\section{Conclusions}

In this work, a computational framework based on the XFEM technique is developed in order to investigate the structural integrity of floating offshore wind turbine foundations. For this purpose, a python code has been developed to randomly assign an extreme value distribution of possible corrosion pit sizes in the hot spot regions at the intersection point between the mooring lines and the floating foundations. The fatigue crack propagation from corrosion pits has been predicted in the presence of a single crack and multiple cracks. The results obtained from numerical simulations are verified through comparison with the Crackwise analysis following the BS7910 procedure. Two sets of analysis for single and multiple cracks were defined using ABAQUS XFEM and the Paris law constants are employed in the model to predict the crack growth rates. For different values of $\mathrm{R}$ ratio, the Walker's formula is used to adjust the Paris law constants. The results have shown that the initial crack size is undoubtedly an important factor to assess whether the structure is at risk of failure or not. For 30 and $20 \mathrm{~mm}$ thick plates the cracks of equal to or larger than $1.5 \mathrm{~mm}$ at high $\mathrm{R}$ ratios will cause crack propagation rates of higher than the general corrosion rate. The 20-year simulation results show that all the cracks that surpass the general corrosion rate of $0.2 \mathrm{~mm} /$ year will eventually cause failure. The geometry of the corrosion pitting location is another important factor that can affect the pace of the crack growth. The corners show particularly high crack growth rates despite having lower mean stress values. It is evident from the results presented in this study that the XFEM technique is a powerful tool for simulation of multiple fatigue cracks in floating offshore wind turbine foundations. 


\section{Acknowledgments}

This work has been funded by SUPERGEN Wind Hub-Flexible Funding Round 4.

\section{References}

[1] Y. H. Lin, C. L. Hsu and S. H. Kao, "Hydrodynamics of the wind float OC3-Hywind with mooring loads estimated by the modular system," Journal of Marine Science and Technology, vol. 24, no. 1, pp. 237-248, 2019.

[2] R. Norris, "RenewableUK releases new global offshore wind market rankings," renewableUK, 19 June 2018. [Online]. Available: https://www.renewableuk.com/news/405601/RenewableUKreleases-new-global-offshore-wind-market-rankings.htm. [Accessed May 2019].

[3] A. Ho, A. Mbistrova and G. Corbetta, "The European offshore wind industry: key 2015 trends and statistics (EWEA report)," $2015 . \quad$ [Online]. https://www.ewea.org/fileadmin/files/library/publications/statistics/EWEA-European-OffshoreStatistics-2015.pdf. [Accessed 2019].

[4] WindEUROPE, "Offshore Wind in Europe: Key trends and statistics 2018," 2 2019. [Online]. Available: https://windeurope.org/wp-content/uploads/files/about-wind/statistics/WindEuropeAnnual-Offshore-Statistics-2018.pdf. [Accessed 5 2019].

[5] SET-Plan, "Offshore Wind Implementation Plan," 13 June 2018. [Online]. Available: https://setis.ec.europa.eu/system/files/setplan_wind_implementationplan_0.pdf. [Accessed 2019].

[6] F. P. Brennan, "A framework for variable amplitude corrosion fatigue materials tests for offshore wind steel support structures," Fatigue \& Fracture of Engineering Materials \& Structures, vol. 37, no. 7, pp. 717-721, 2014.

[7] Y. H. Bae and M. H. Kim, "Aero-elastic-control-floater-mooring coupled dynamic analysis of floating offshore wind turbine in maximum operation and survival conditions," Journal of Offshore Mechanics and Arctic Engineering, vol. 136, no. 2, 2014:020902.

[8] N. O. Larrosa, R. Akid and R. A. Ainsworth, "Corrosion Fatigue: a review of damage tolerance models," International Materials Reviews, vol. 5, no. 63, pp. 238-308, 2018.

[9] OFFSHORE STANDARD DNV-OS-J101, "Design of Offshore Wind Turbine Structures," DET NORSKE VERITAS AS, 2014.

[10 R. E. Melchers, "The changing character of long term marine corrosion of mild steel," 2010. ]

[11 R. Melchers, "The effect of corrosion on the structural reliability of steel offshore structures," ] Corrosion Science, vol. 47, no. 10, pp. 2391-2410, 2005a. 
[12 R. Akid, "The role of stress-assisted localized corrosion in the development of short fatigue ] cracks.," In Effects of the environment on the initiation of the crack growth. ASTM International, 1997.

[13 J. T. Burns, J. M. Larsen and R. P. Gangloff, "Driving forces for localized corrosion-to-fatigue crack ] transition in Al-Zn-Mg-Cu," Fatigue \& Fracture of Engineering Materials \& Structures, vol. 34, no. 10, pp. 745-773, 2011.

[14 D. Hoeppner, "Models for prediction of fatigue lives based upon a pitting corrosion fatigue process," ] Fatigue Mechanics, ASTM International, 1979.

[15 T. Lindley , P. McIntyre and P. Trant, "Fatigue crack initiation at corrosion pits," Met Technol, vol. ] $9,1982 ' 135-142$.

[16 S. Kawai and K. Kasai, "Considerations of allowable stress of corrosion fatigue (focused on the ] influence of pitting)," Fatigue Fract Eng Mater Struct., vol. 8, no. 2, pp. 115-127, 1985.

[17 G. S. Chen, M. Gao, D. G. Harlow and R. P. Wei, "Corrosion and Corrosion Fatigue of Airframe ] Aluminum Alloys," FAA/NASA International Symposium on Advanced Structural Integrity Methods for Airframe Durability and Damage Tolerance, pp. 157-173, 1994.

[18 S. I. Rokhlin, J. Y. Kim, H. Nagy and B. Zoofan, "Effect of pitting corrosion on fatigue crack initiation ] and fatigue life," Engineering Fracture Mechanics, vol. 62, no. 4-5, pp. 425-444, 1999.

[19 Q. Y. Wang, R. M. Pidaparti and M. J. Palakal, "Comparative Study of Corrosion-Fatigue in Aircraft ] Materials," AIAA Journal, vol. 39, no. 2, pp. 325-330, 2001.

[20 NERL, "NWTC Information Portal: Software," NREL, 2019. [Online]. Available: ] https://nwtc.nrel.gov/Software. [Accessed 2019].

[21 S. D. Downing and D. F. Socie, "Simple Rainflow Counting Algorithms," International journal of ] fatigue, vol. 4, no. 1, pp. 31-40, 1982.

[22 N. E. Dowling, "Mean stress effects in stress-life and strain-life fatigue," SAE Technical Paper ] (2004-01-2227), 2004.

[23 G. Glinka and J. C. Kam, "Rainflow Counting Algorithms," International Journal of Fatigue, vol. 9, ] no. 3, pp. 223-228, 1987.

[24 BS 7910, "Guide on methods for assessing the acceptability," London: British Standard Institution, ] 2013.

[25 X. Qian, "Fracture representation and assessment for tubular offshore structures," in Handbook of ] Materials Failure Analysis with Case Studies from the Oil and Gas Industry, ButterworthHeinemann, 2016, pp. 371-392.

[26 I. Milne, B. Karihaloo and R. O. Ritchie, "Structural Integrity Assurance," in Comprehensive ] Structural Integrity, Pergamon, 2003, pp. 1-24.

[27 I. A. Chavez and R. E. Melchers, "Pitting corrosion in pipeline steel weld zones," Corrosion ] Science, vol. 53, no. 12, pp. 4026-4032, 2011. 
[28 DNV Standard, "DNVGL - RP- C203: Fatigue design of offshore steel structures," DNV GL AS, ] 2016.

[29 Dassault Systèmes, "SIMULIA Advantage Support," 3DS, 2019. [Online]. Available: ] https://www.3ds.com/products-services/simulia/support/documentation/. [Accessed 2019].

[30 L. P. Pook, "Analysis and Application of Fatigue Crack Growth Data", in "A General Introduction to ] fracture Mechanics," Journal of Strain Analysis, vol. 10, no. 4, pp. 242-250, 1975.

[31 P. Paris and F. Erdogan, "A critical analysis of crack propagation laws, Journal of Basic ] Engineering," Transactions of the American Society of Mechanical Engineers, pp. 528-534, 1963.

[32 R. E. Melchers, " Pitting corrosion of mild steel in marine immersion environment-Part 2: ] Variability of maximum pit depth 60.10 (2004): 937-944.," Corrosion, vol. 60, no. 10, pp. 937-944, 2004.

[33 R. E. Melchers, "Pitting Corrosion of mild steel in marine immersion environment - Part 1: Maximum ] pit depth," Corrosion, vol. 9, no. 8, pp. 824-836, 2004.

[34 M. Nicodemi, Extreme Value Statistics: Theory, Techniques, and Applications, New York: Springer ] New York, 2012, pp. 1066-1072.

[35 P. M. Aziz, "Application of the statistical theory of extreme values to the analysis of maximum pit ] depth data for aluminum," Corrosion, vol. 12, no. 10, pp. 35-46, 1956.

[36 A. Valor, F. Caleyo, L. Alfonso, J. C. Velázquez and J. M. Hallen, "Markov chain models for the ] stochastic modeling of pitting corrosion," Mathematical Problems in Engineering, 2013.

[37 R. E. Melchers, "Representation of uncertainty in maximum depth of marine corrosion pits," ] Structural Safety, vol. 27, no. 4, pp. 322-334, 2005.

[38 J. E. Strutt, J. R. Nicholls and B. Barbier, "The prediction of corrosion by statistical analysis of ] corrosion profiles," Corrosion Science, vol. 25, no. 5, pp. 305-315, 1985.

[39 R. E. Melchers and M. Ahammed, "Maximum pit depth variability in water injection pipelines," in ] Twenty-eighth International Ocean and Polar Engineering Conference, Sapporo, Japan, 2018.

[40 V. G. Kulkarni, Modeling and Analysis of Stochastic Systems, Second Edition, Chapman \& Hall, ] 2010.

[41 A. Momber, "Corrosion and corrosion protection of support structures for offshore wind energy ] devices (OWEA)," Materials and Corrosion, vol. 62, no. 5, pp. 391-404, 2011.

[42 P. Higgins and A. Foley, "The evolution of offshore wind power in the United Kingdom," Renewable ] and sustainable energy reviews, vol. 37, pp. 599-612, 2014.

[43 R. E. Melchers, "Recent Progress in the Modeling of Corrosion of Structural steel immersed in ] seawater," Journal of infrastructure systems, vol. 12, no. 3, pp. 154-162, 2006.

[44 A. Mehmanparast, F. Brennan and I. Tavares, "Fatigue crack growth rates for offshore wind ] monopile weldments in air and seawater: SLIC inter-laboratory test results," Materials \& Design, vol. 114, pp. 494-504, 2017. 
[45 C. A. R. P. Baptista, A. M. L. Adib, M. A. S. Torres and V. A. Pastoukhov, "Describing fatigue crack ] growth and load ratio effects in Al 2524 T3 alloy with an enhanced exponential model," Mechanics of Materials, vol. 51, pp. 66-73, 2012.

[46 A. Mehmanparast, J. Taylor, F. Brennan and I. Tavares, "Experimental investigation of mechanical ] and fracture properties of offshore wind monopile weldments: SLIC interlaboratory test results," Fatigue \& Fracture of Engineering Materials \& Structures, vol. 41, no. 12, pp. 2485-2501, 2018.

[47 A. M. de Jesus, R. Matos, B. F. Fontoura, C. Rebelo, L. S. de Silva and M. Veljkovic, "A comparison ] of the fatigue behavior between S355 and S690 steel grades," Journal of Constructional Steel Research, vol. 79, pp. 140-150, 2012.

[48 Y. H. Bae, M. H. Kim, S. W. Im and I. H. Chang, "Aero-elastic-control-floater-mooring coupled ] dynamic analysis of floating offshore wind turbines," in The Twenty-first International Offshore and Polar Engineering Conference, Maui, Hawaii, 2011.

[49 Hywind Scotland, Statoil, "Hywind Scotland Pilot Park Project Plan for Construction Activities," ] 2017. [Online]. Available: http://marine.gov.scot/sites/default/files/00516548.pdf. [Accessed 04 2019].

[50 K. E. Steen, "Hywind Scotland - status and plans," 2016. [Online]. Available: ] https://www.sintef.no/globalassets/project/eera-deepwind2016/presentations/steen_openingsession.pdf. [Accessed 2019].

[51 M. Matsuishi and T. Endo, "Fatigue of metals subjected to varying stress," Japan Soc. Mech. ] Engineering, 1968.

[52 SIMULA, "ABAQUS Documentation," 2017. [Online]. Available: ] https://www.sharcnet.ca/Software/Abaqus/6.14.2/v6.14/books/usb/default.htm?startat=pt01ch03s 02abx11.html. [Accessed 2019].

[53 A. Kolios, L. Wang, A. Mehmanparast and F. Brennan, "Determination of stress concentration ] factors in offshore wind welded structures through a hybrid experimental and numerical approach," Ocean Engineering , vol. 178, pp. 38-47, 2019.

[54 J. C. Velázquez, J. M. Van Der Weide, E. Hernández and H. H. Hernández, "Statistical modelling ] of pitting corrosion: extrapolation of the maximum pit depth-growth," Int. J. Electrochem. Sci, vol. 9, no. 8, pp. 4129-4143, 2014.

[55 M. Nuhi, T. A. Seer, M. Modarres and A. Seibi, "Reliability analysis for degradation effects of pitting ] corrosion in carbon steel pipes," Procedia Engineering , vol. 10, pp. 1930-1935, 2011.

[56 G. Masi, F. Metteucci and J. Tacq, "State of the Art Study on Materials and Solutions against ] Corrosion in Offshore Structures," NeSSIE, 2018.

[57 "Offshore wind operational report," THE CROWN ESTATE, London, 2018. ]

[58 Y. Kondo, "Prediction of fatigue crack initiation life based on pit growth," Corrosion, vol. 45, no. 1, pp. 7-11, 1989. 
[59 A. Valor, F. Caleyo, L. Alfonso, D. Rivas and J. M. Hallen, "Stochastic modeling of pitting corrosion: A new model for initiation and growth of multiple corrosion pits," Corrosion Science, vol. 49, no. 2, pp. 559-579, 2007.

[60 CARBON TRUST, "Offshore wind power: big challange, big opportunity, Maximizing the ] environmental, economic and security benefits," October 2008. [Online]. Available: https://www.carbontrust.com/media/42162/ctc743-offshore-wind-power.pdf. [Accessed 2019]. 